\title{
8
}
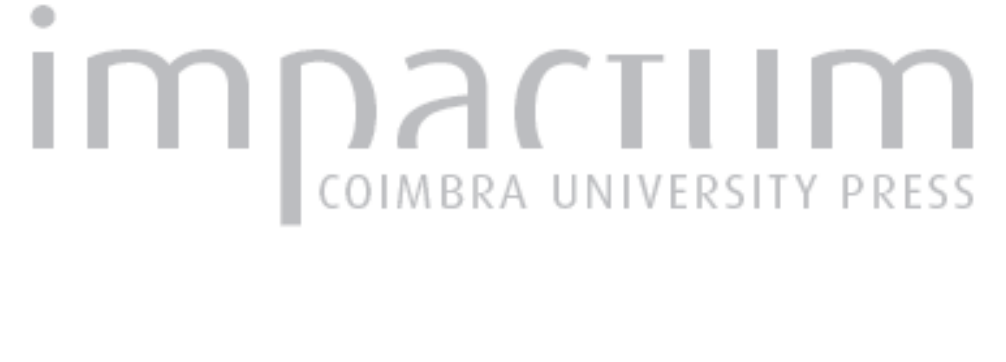

\section{Epistolografía amorosa y familiar en Moralia de Plutarco}

Autor(es): Vicente Sánchez, Ana

Publicado por: International Plutarch Society

URL persistente:

URl:http://hdl.handle.net/10316.2/36394

DOI:

DOI:http://dx.doi.org/10.14195/0258-655X_6_5

Accessed : $\quad$ 26-Apr-2023 15:49:13

A navegação consulta e descarregamento dos títulos inseridos nas Bibliotecas Digitais UC Digitalis, UC Pombalina e UC Impactum, pressupõem a aceitação plena e sem reservas dos Termos e Condições de Uso destas Bibliotecas Digitais, disponíveis em https://digitalis.uc.pt/pt-pt/termos.

Conforme exposto nos referidos Termos e Condições de Uso, o descarregamento de títulos de acesso restrito requer uma licença válida de autorização devendo o utilizador aceder ao(s) documento(s) a partir de um endereço de IP da instituição detentora da supramencionada licença.

Ao utilizador é apenas permitido o descarregamento para uso pessoal, pelo que o emprego do(s) título(s) descarregado(s) para outro fim, designadamente comercial, carece de autorização do respetivo autor ou editor da obra.

Na medida em que todas as obras da UC Digitalis se encontram protegidas pelo Código do Direito de Autor e Direitos Conexos e demais legislação aplicável, toda a cópia, parcial ou total, deste documento, nos casos em que é legalmente admitida, deverá conter ou fazer-se acompanhar por este aviso.

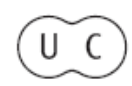




\section{PLOUTARCHOS, n.s.}

Scholarly Journal o

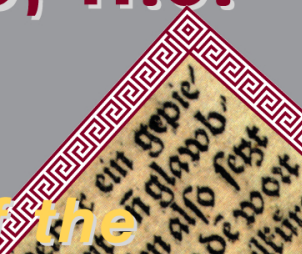

INTERNATIONAL PLUT A N NOS

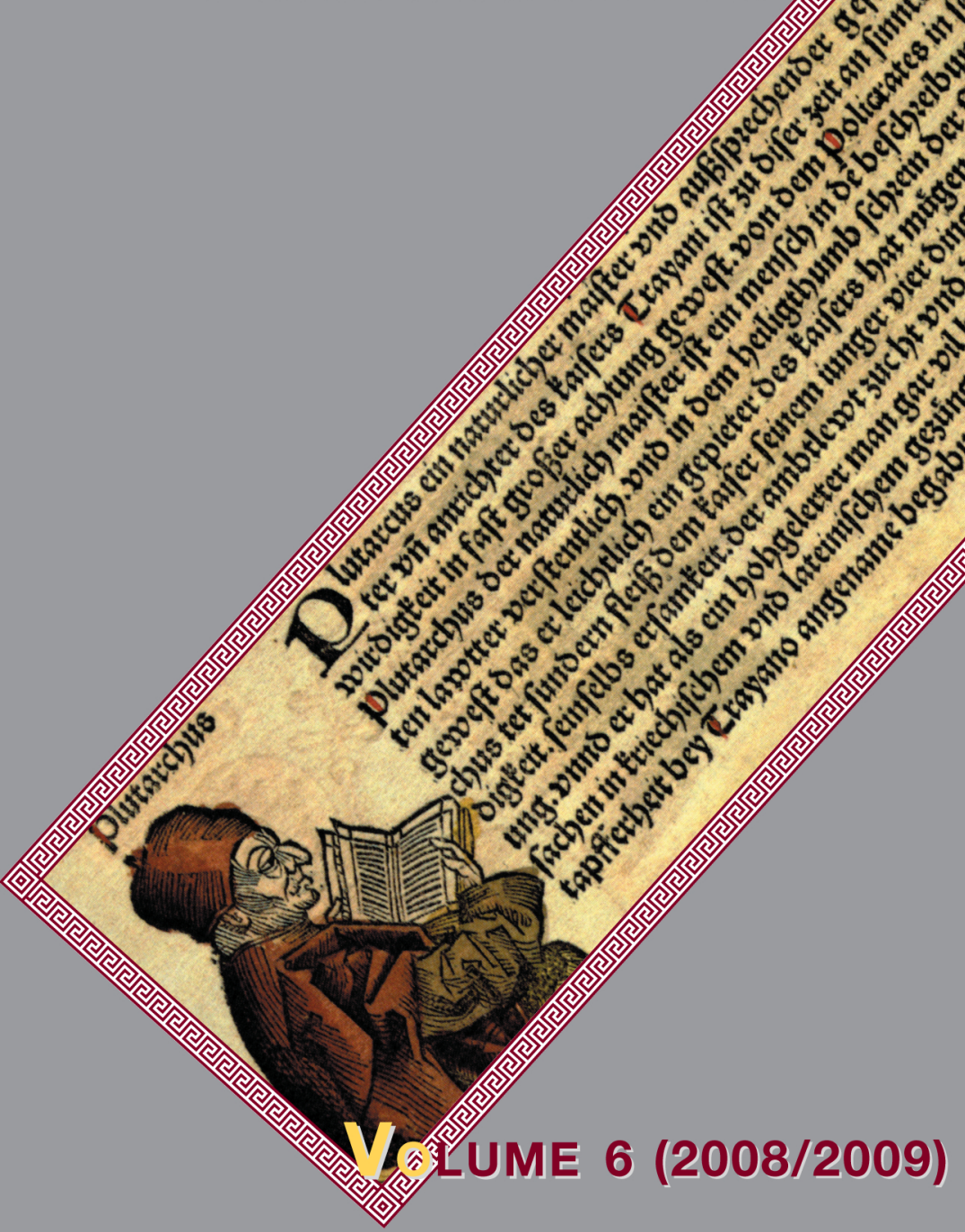

UNIVERSITY of Málaga (SPAin)

Utah State UniVersity, Logan, Utah (U.S.A.) 


\section{Epistolografía amorosa y familiar en Moralia de Plutarco por \\ Ana Vicente Sánchez \\ Universidad de Zaragoza \\ ana@unizar.es}

es definir el uso que Plutarco hacía de un

Las páginas que siguen pretenden ser una tipo específico de epistolografía, cuyas contribución al estudio de la epistolografía conclusiones han de resultar de utilidad para en la obra de Plutarco ${ }^{1}$. La carta en Grecia, conocer mejor este elemento y de qué forma debido a su importancia como medio de recurría el queronense a semejante medio de comunicación y a su explotación como comunicación. En concreto se van a estudiar género literario, forma parte de la vida las cartas que pertenecen al ámbito de la cotidiana $\mathrm{y}$, asimismo, progresivamente vida personal, aquéllas relacionadas con la del ámbito literario. Nuestra intención aquí vida amorosa y familiar ${ }^{2}$, dentro de la gran

1 Este trabajo se ha realizado bajo los auspicios del Proyecto de Investigación H52 (Grupo BYBLION) de la Dirección General de Investigación Innovación y Desarrollo (DGA). Mi agradecimiento desde estas líneas a la Fondation Hardt pour l'Étude de l'Antiquité Classique (Vandoeuvres, Suiza), en la que durante la primavera de 2007 disfruté de una beca para la investigación de la epistolografía en la obra de Plutarco.

2 Sería este un subtipo de epistolografía que entraría dentro de las clasificaciones tradicionales en el apartado de cartas incluidas en otros géneros literarios por una parte (J. Sykutris, 1931, cols. 208-210; J. Schneider, 1954, cols. 568 ss.; B. Kytzler, 1965, cols. 497 s.; Ma . L. BARRIO VEGA, 1991, pp. 128 ss.), y, por otra, siguiendo la catalogación 
variedad de tipos epistolares que Plutarco composiciones la variedad en cuanto al incluye en Moralia. En este delimitado contenido y a la finalidad ${ }^{3}$. Así, son las campo tenemos cartas entre miembros de más numerosas aquéllas que contienen una familia: entre cónyuges (314 A-B y B- claramente peticiones (254 D, 252 A, C, 252 A y 799 E); de una madre a su hijo, 273 E-F, 760 C), que también pueden como la de Olimpíade a Alejandro $(180 \mathrm{D}$, expresarse a través de preguntas (1099 $332 \mathrm{~F}-333 \mathrm{~A}, 340 \mathrm{~A}$ ) o las anónimas de unas D, y la primera carta de $333 \mathrm{~A}$ ), por lo espartanas a sus respectivos vástagos (241 que también encontraremos cartas "de A, 241D, $241 \mathrm{D}-\mathrm{E}$ ); para un hijo de su padre respuesta" (la segunda carta de $333 \mathrm{~A}$, (273 E-F) y viceversa (109 C-D); y entre o la carta-tratado de 1012 B-1030 C); hermanos (254 D y $1098 \mathrm{C}-\mathrm{D})$. Referentes asimismo son frecuentes las cartas que a cuestiones amorosas fuera del ámbito fa- consisten en un reproche por un error o miliar podemos contar con dos entre Ale- una crítica (la segunda carta de $333 \mathrm{~A}$, jandro y un amigo (760 C, 1099 D y las 241 A, 241 D, 241 D-E, 109 C-D) o en un dos de 333 A). Finalmente, es inevitable ataque o acusación (314 A-B y B-C, 180 mencionar aquellas obras enmarcadas en el formato epistolar dirigidas o dedicadas a determinados personajes, frecuentemente amigos o familiares (608 A-612 B y 1012 B-1030 C).

D); por otra parte, hay una carta de opinión personal y carácter filosófico (1098 C-D) y algunas confidenciales cuyo contenido no se nos desvela explícitamente (332 F-333

A fin de lograr una clasificación de los ejemplos que Plutarco nos ofrece de este tipo de epistolografía, además del remitente y destinatario, debe tenerse en cuenta el contenido. $Y$ este es diver-

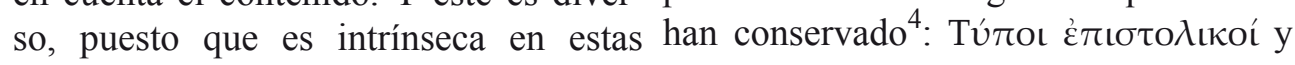

establecida por H. Koskenniemi respecto de cartas en papiro, según la relación entre remitente y destinatario (H. KosKENNIEMI, 1956, pp. 88 ss. y 11 ss.); de forma similar sirve el criterio del grado de privacidad, aunque parte de ellas habría que incluirlas en la categoría de cartas "no reales" (W. G. Dоту, 1969, pp. 196 s. en su clasificación de la epistolografía helenística; G. SCARPAT, 1972, pp. 474 s., 486 ss., 495 ss.; H. Hunger, 1978, pp. 203 ss. para la epistolografía bizantina; P. Cugusi, 1990, pp. 395 ss.; Ma . L. BARRIO Vega, 1991, pp. 128 ss.; M. L. JR. StiRewalt, 1993, pp. 10 ss.).

3 Cf. E. SuÁreZ DE LA Torre, 1988, pp. 181 s.; J. Frösen, Prolegomena to study of the Greek language in the first centuries A. D. The problem of Koine and Atticism, Helsinki, 1974, pp. $114 \mathrm{~s}$.

4 De la antigüedad de la ejercitación práctica en distintos tipos epistolares, así como de la relación entre la retórica y la epistolografía, dan fe, por ej., algunas de las cartas los Pariser Papyri: el número 63 recoge cartas de los años 164-163 a.C. que se reconocen como ejercicios escolares con influencias retóricas; cf. W. SchмID, "Ein epistolographisches 


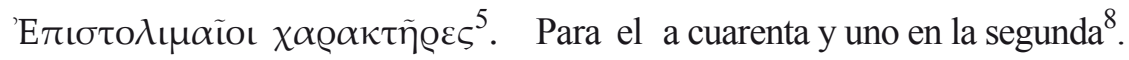
primero, la cronología atribuida oscila entre el siglo II a. C. y el III, aunque la mayoría de los estudios suelen fijar su punto de partida en torno a los siglos II/I a.C. ${ }^{6}$, por lo que evidentemente nos interesará de forma

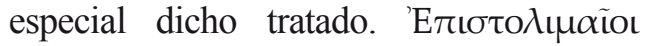
$\chi \alpha \varrho \alpha \kappa \tau \tilde{\varrho} \varepsilon \varepsilon$, , por su parte, se muestra claramente como el producto de una escuela retórica que suele datarse entre los siglos misma más de un tipo 9 . Con su petición,

Así, como ya se ha comentado, varias de las cartas que tenemos expresan una petición, que aparece en los manuales

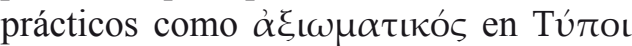

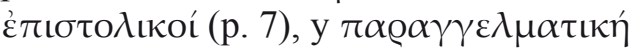

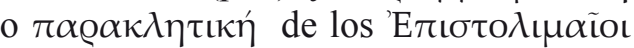
$\chi \alpha \varrho \alpha \kappa \tau \tilde{\eta} \varrho \varepsilon \varsigma$ (pp. 16, 22, 24 s.), sin olvidar que una carta podía contener en sí $\mathrm{IV} \mathrm{y} \mathrm{VI}^{7}$. Las diferencias entre ambas obras la naxia Polícrite, va a salvar a su pueblo; nos dan idea de la evolución y desarrollo de capturada por los eritreos, se las ingenia la teoría epistolar, pues en la más antigua para introducir un mensaje escrito sobre teníamos veintiún tipos que ya han pasado una tablilla de plomo dentro de una

Übungsstück unter den Pariser Papyri", Neue Jahrbücher für Philologie und Paedagogik, 145 (1892), pp. 695 ss.; U. WILCKEN, Urkunden der Ptolomemäerzeit (Älttere Funde). Erster Band: Papyri aus Unterägypten, Berlin-Leipzig, 1927, pp. 471 ss. y 622 ss. (las cartas aparecen en esta obra numeradas como 110, 111, 144 y 145); H. KosKenNIEMI, 1956, pp. 57 ss.

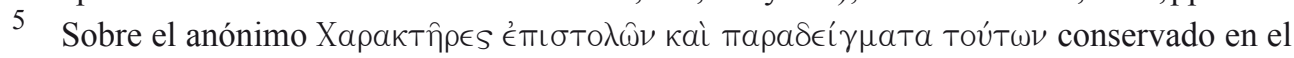
códice Vat. Gr. 344, y su relación con el texto de "PseudoLibanio", vid. A. Luppino, "Una redazione inedita di caratteri epistolari”, Annali della Facoltà di Lettere e Filosofia, VII (1957), pp. 145 ss.

$6 \mathrm{Y}$, aunque éste en concreto procede del Egipto helenístico, se considera que igualmente

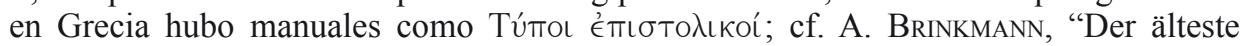
Briefsteller", RhM, 64 (1909), pp. 313 ss.; V. Weichert, 1910, pp. XVII ss.; H. KOSKENNIEMI, 1956, pp. 20 y 54 ss.; J. L. White, 1986, pp. 189 ss..; A. J. MalHerbe, 1988, pp. 4 ss.; E. SuÁrez de la Torre, 1988, pp. 191 ss.

7 De este manual hay dos tradiciones manuscritas, una atribuida a Libanio y otra a Proclo, y E. Suárez de la Torre señala su composición en torno al siglo V; vid. E. SuÁREZ DE LA TORRE, 1988, p. 197 y también 1979, pp. 34 s.; $c f$. también H. KosKENNIEMI, 1956, pp. 56 s.; H. Hunger, 1978, p. 200; G. A. Kennedy, 1983, pp. 71 s.; J. T. ReEd, 1997, p. 174 s.

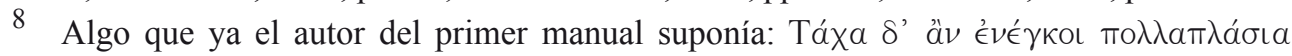

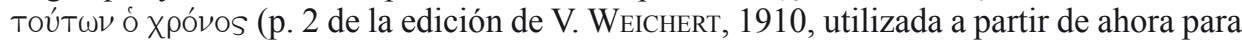
ambos manuales).

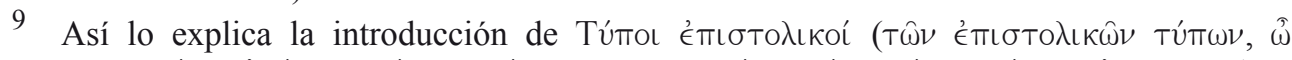

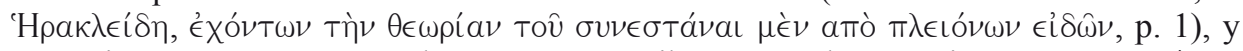
aconseja, por otra parte, que las cartas se escriban como de un amigo para otro -тútros $\phi \iota \lambda \iota \kappa^{\prime}$-, $^{-}$en la idea de que conseguirán mejor sus propósitos al comportarse como

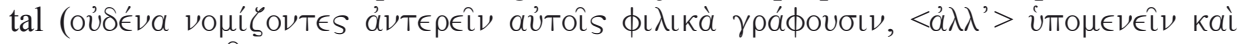

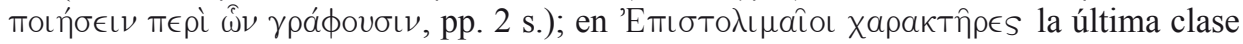

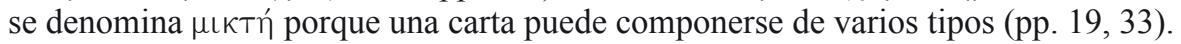


torta que su secuestrador Diogneto le peligrosa para los dominios del tirano, ha permitido enviar a sus hermanos con que ha engañado, robado y encarcelado motivo de una festividad celebrada por a sus mujeres e hijos; para librarse de los eritreos. Este pasaje contiene dos ellos pretende Aristotimo presionar a sus mensajes, uno oral al portador de la torta, mujeres de modo que escriban y envíen con el encargo de advertir a sus hermanos una carta a sus maridos pidiéndoles que que sólo ellos deben consumirla, y el salgan de la peligrosa fortificación ${ }^{13}$; sin mensaje sobre el plomo ${ }^{10}$ indicándoles embargo, Megisto, mujer de Timoleón, la idoneidad de un ataque dado el estado se niega en nombre de todas y llega de embriaguez y fiesta que reinaba incluso a ofrecer la vida de su propio hijo entre los enemigos ${ }^{11}$. En esa misma como prueba de su valentía. También obra, Virtudes de mujeres, se menciona una petición ${ }^{14}$, pero más bien procedente otra carta de las que llamaríamos de del ámbito sentimental mezclado con los petición ${ }^{12}$, aunque en realidad no llegó negocios, es la que hace mediante una a escribirse; algunos exiliados de Élide, carta Alejandro a Teodoro, pues quiere tiranizada cruelmente por Aristotimo, comprarle su cantante, siempre que éste han ocupado una plaza fuerte que resulta no la $a^{15}{ }^{15}$. En Cuestiones romanas

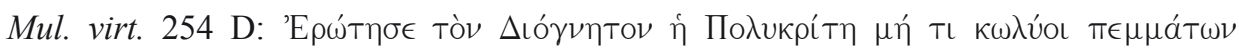

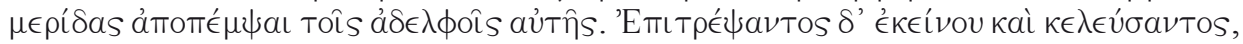

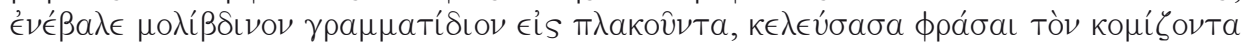

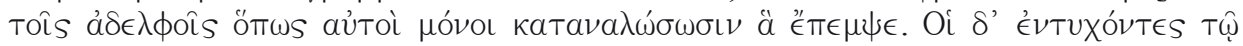

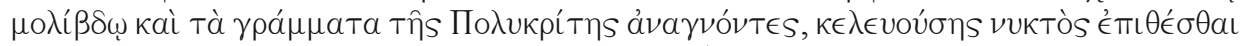

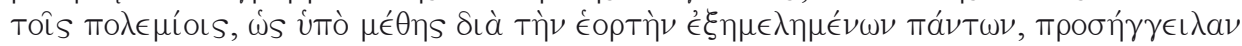

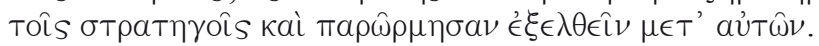

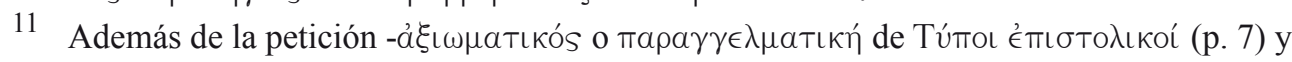

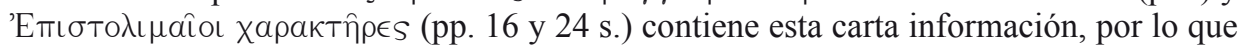

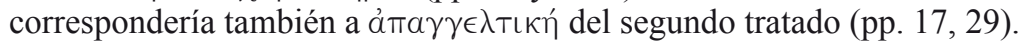

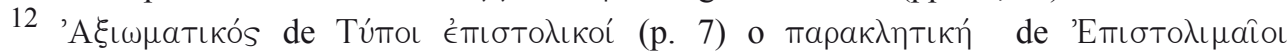

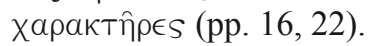

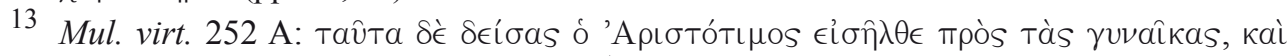

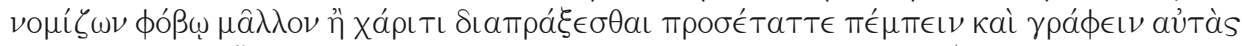

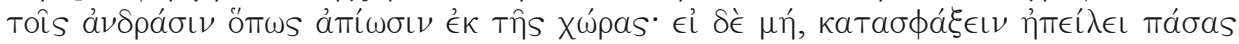

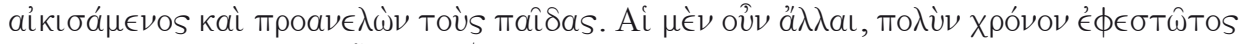

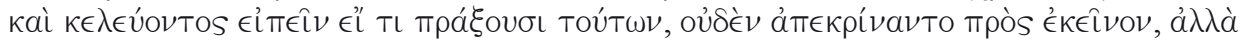

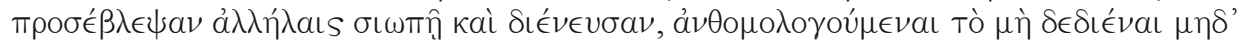

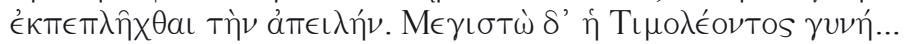

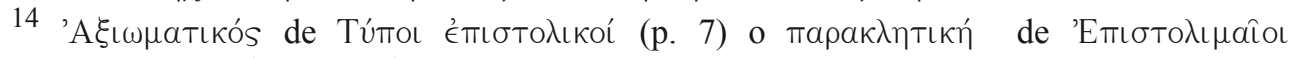
характиিрєs (pp. 16, 22).

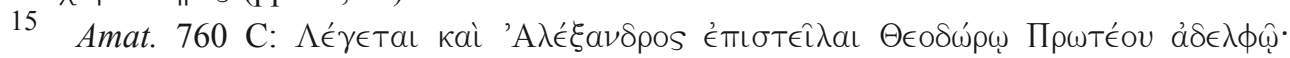

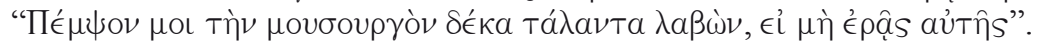


explica Plutarco una cuestión a través ofreciéndole la venta de unos atractivos del ejemplo de un personaje conocido: muchachos $^{19}$, estuvo a punto de relevarlo es una carta de Catón el Viejo a su hijo ${ }^{16}$ de su cargo. La misma situación explicada en la que le pide que regrese si ha sido un poco más detalladamente ${ }^{20}$ aparece en licenciado al haber completado su tiempo Sobre la fortuna o virtud de Alejandro, en el ejército, o que, si debe permanecer, como un ejemplo más que sustenta la tome de su general el permiso para atacar $\sigma \omega \phi \emptyset 0 \sigma u ́ v \eta$ de Alejandro, comparado y destruir al enemigo ${ }^{17}$. ahora con filósofos como Sócrates ${ }^{21}$.

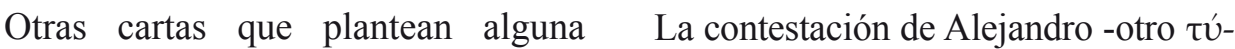

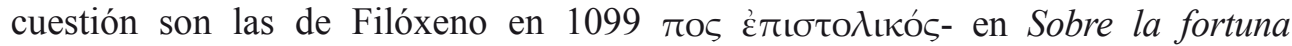
$\mathrm{D}$ y en 333 A, remitiendo, en este caso, o virtud de Alejandro a la propuesta de al llamado tipo "interrogativo" por Filóxeno ${ }^{22}$ sirve como ejemplo de uso de los manuales prácticos ${ }^{18}$. En Sobre la este medio de comunicación para transmiimposibilidad de vivir placenteramente tir un reproche, contenido ciertamente hasegún Epicuro, según Plutarco, cuando bitual en la epistolografía griega e incluido Alejandro recibe una carta de Filóxeno en las clasificaciones antiguas ${ }^{23}$. También

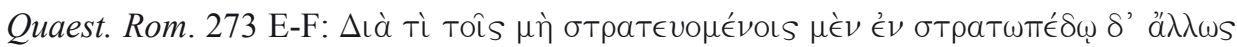

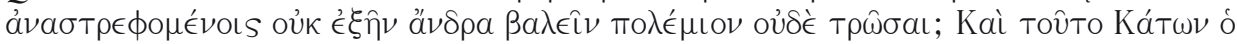

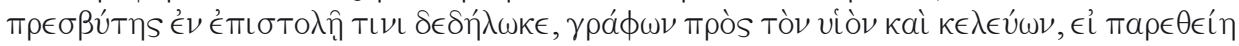

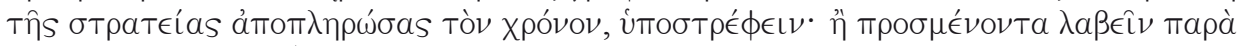

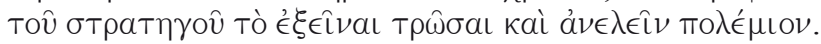

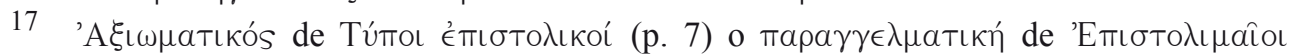

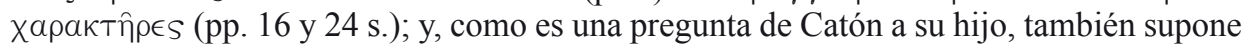

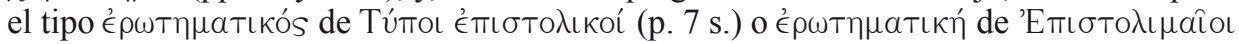

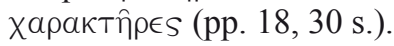

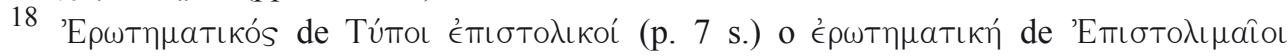
характиিрєS (pp. 18, 30 s.).

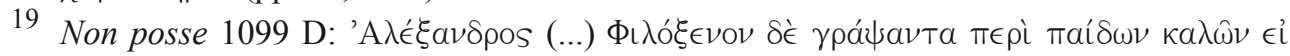

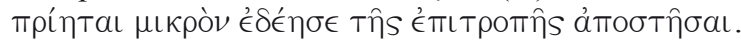

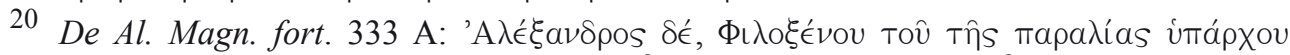

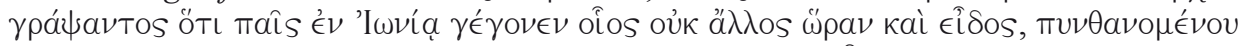

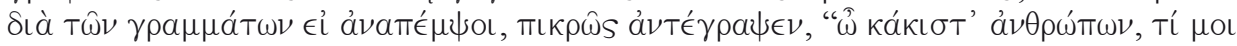

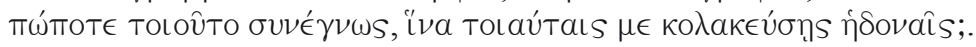

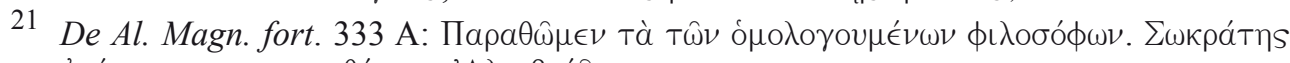

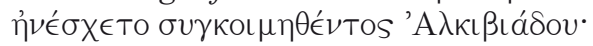

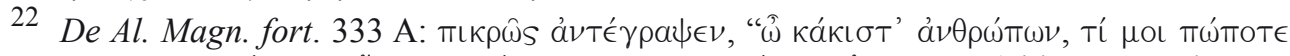

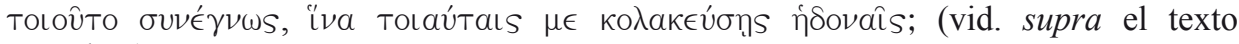
completo).

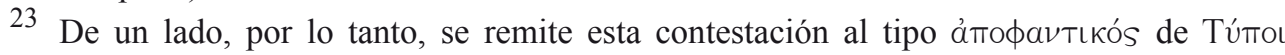

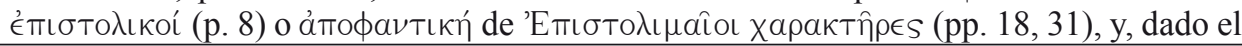


reprochan ${ }^{24}$ las cartas de las espartanas ser su hijo Eutínoo le entrega una nota en anónimas a sus hijos ${ }^{25}$, una vez conocido la que se critica la forma de pensar de los su mal comportamiento en el extranjero, hombres, aclarándole que la de su hijo incluyendo, además, amenazas ${ }^{26}$. Una era una muerte predestinada, ya que vivo reprimenda constituye la carta que no era bueno ni para él mismo ni para Eutínoo hace leer a su padre Elisio, quien sus padres ${ }^{28}$. Tenemos, por lo tanto, una ha recurrido a la necromancia-adivinación epístola que se clasificaría como "mixta" por medio de la evocación de los muertos- según los tratados prácticos: además de para intentar averiguarsi su hijo ha muerto cierto tono de reproche ${ }^{29}$, informa a un envenenado ${ }^{27}$. De este modo, Elisio tiene padre de la buena situación de su hijo una visión en la que alguien que parece fallecido ${ }^{30}$, en una obra que pretende

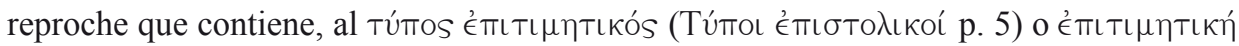

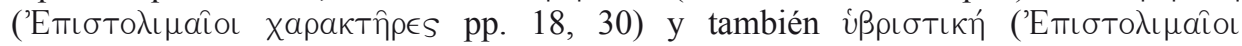
Характиিрєs (pp. 17, 28).

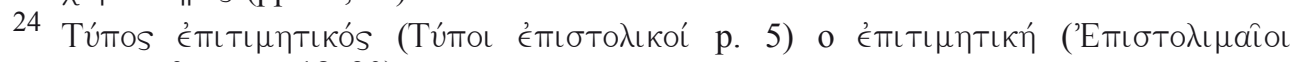
характпिрєS pp. 18, 30).

25

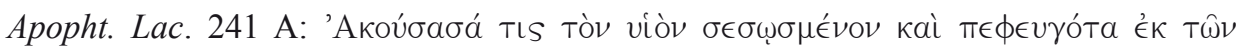

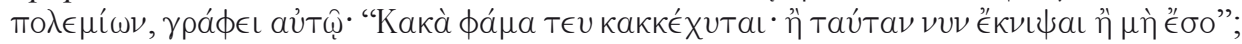

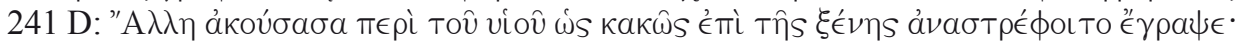

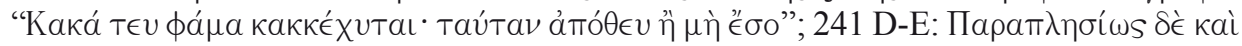

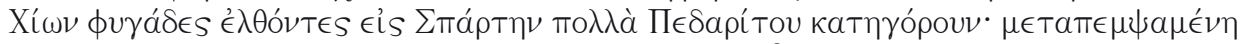

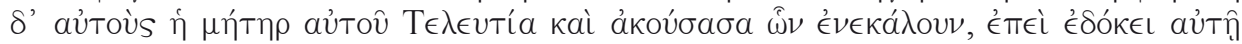

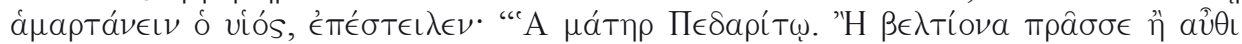

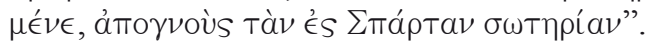

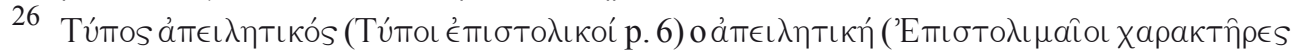
pp. 16, 24).

27 Sobre el proceso, el sentido y la ubicación de esta consulta y similares, vid. D. Ogden, Greek and Roman Necromancy, Princeton-Oxford, 2001, pp. 17 ss. y 75 ss.

28 Cons. ad Apoll. 109 C-D:

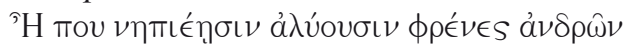

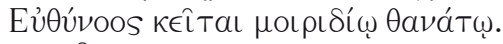

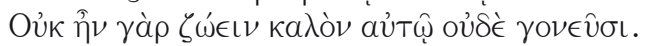

De esta forma edita el texto -no muy claro en los manuscritos- F. C. BАвBітT, 1971; los problemas de la tradición manuscrita han supuesto numerosas correcciones en las ediciones, sobre todo a partir de R. Hercher, para que coincidan en lo posible con los versos que Cicerón escribe al narrar esta misma historia en las Tusculanae Disputationes I 48.115; sobre las distintas lecturas y posibles correcciones vid. A. Vicente SÁnChEZ, "Un mensaje del más allá: Cons. ad Apoll. 109 C-D” (en prensa).

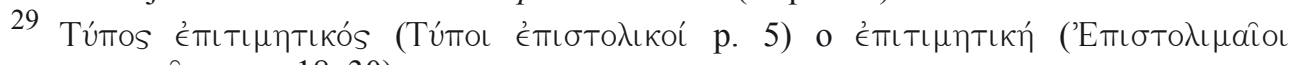
характиিрєS pp. 18, 30).

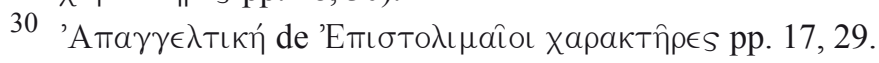


consolar $^{31}$ a Apolonio por la pérdida de cuatro ocasiones, tres en Moralia y una su vástago.

en las Vidas ${ }^{35}$. En Máximas de reyes

Por otra parte, pertenecen a una categoría distinta las difamaciones y acusaciones $^{32}$ falsas recogidas en sendas cartasqueFedra ${ }^{33}$ y Gidica $^{34}$ dejan para sus maridos acerca de sus hijastros. También las difamaciones sobre otra persona son el contenido de una carta de Olimpíade a su hijo Alejandro, pero no es su contenido $y$ generales será el único lugar en el que se desvele algo del contenido de la misiva ${ }^{36}$, siendo lo importante la reacción de Alejandro al permitir a Hefestión que la leyera también, puesto que esa era su costumbre: simplemente quitándose su anillo puso el sello en la boca de su amigo, para de ese modo sellar su silencio. Los otros dos testimonios que tenemos de este lo que parece importarle Plutarco de esta episodio aparecen tan sólo caracterizados carta, sino las circunstancias de su lectura como émı y sus correspondientes interpretaciones. cuenta de la insignificancia de la carta De hecho estas mismas son diversas, en sí misma, puesto que es el contexto dado que el de Queronea la emplea en lo que incita a Plutarco a utilizarla ${ }^{37}$.

31 La carta, en definitiva, es el consuelo que el padre encuentra en formato epistolar, esto es,

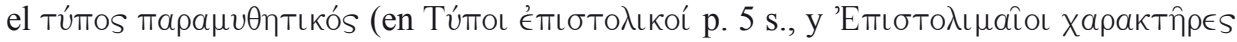
pp. 17, 28).

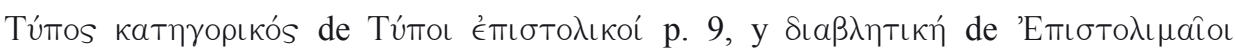
характиিреs pp. 18, 30.

33 Parallel. Graec. et Rom. 314 A-B: Tท̂s Sè mpoaı

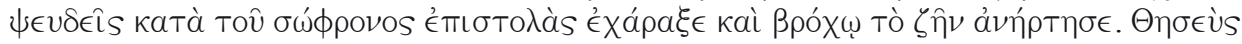

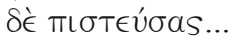

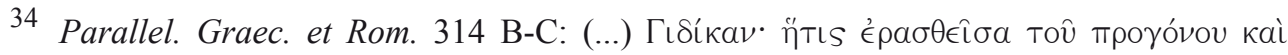

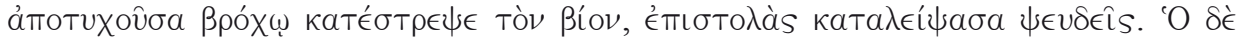

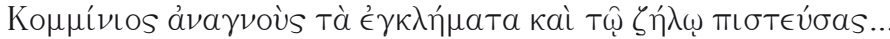

35 Alex. 39.8.

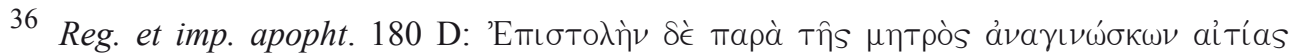

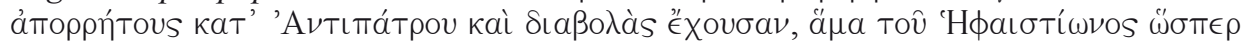

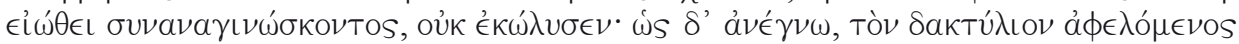

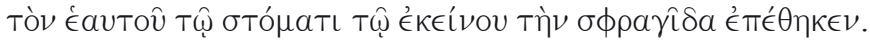

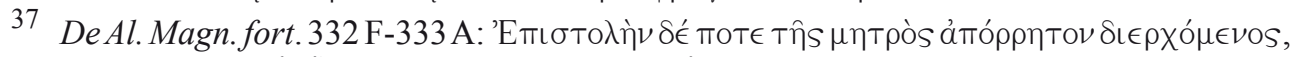

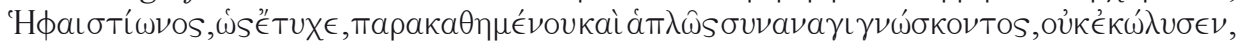

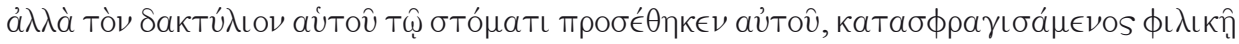

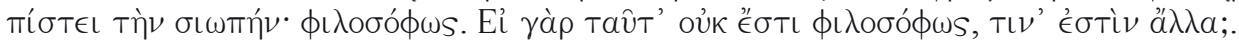

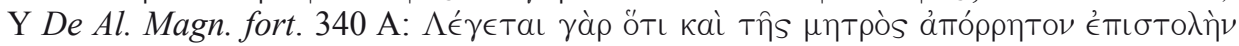

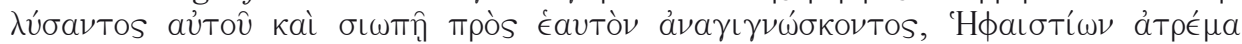

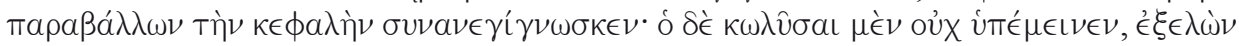

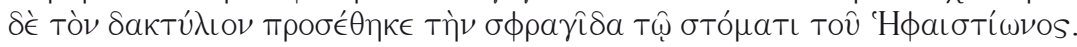


Del mismo modo aparece una carta de comparte con él su alegría por haber la que sólo sabemos que el contenido era aprendido a agradar de manera correcta

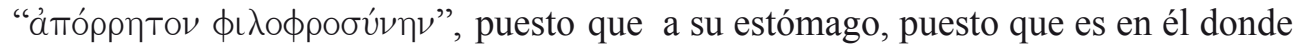
los atenienses, al interceptar este correo y se halla lo mejor.

darse cuenta de que era de Filipo para su esposa Olimpíade ${ }^{38}$ la respetaron ${ }^{39}$.

Porúltimo ha dehacerse referencia alas

Cartas de tipo exhortativo ${ }^{40}$ encontra- del soporte epistolar ${ }^{42}$, algo evidente en los mos en Sobre la imposibilidad de vivir escritos precedidos de encabezamientos placenteramente según Epicuro, que epistolares aunque también en aquéllos recoge dos fragmentos enviados por simplemente dirigidos a otras personas Metrodoro a su hermano sobre la mejor puede rastrearse dicho soporte. Con forma forma de vivir para ellos, siguiendo las de carta y dirigidos a familiares, tenemos enseñanzas de Epicuro $^{41}$ : no es asunto un Escrito de consolación a su mujer y suyo salvar la patria, ni ser coronados un tratado filosófico, Sobre la generación por su sabiduría, sino dedicarse a comer del alma en el "Timeo"43, destinado a

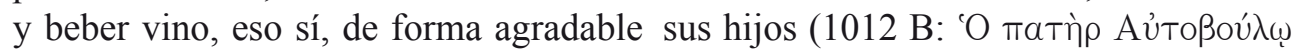

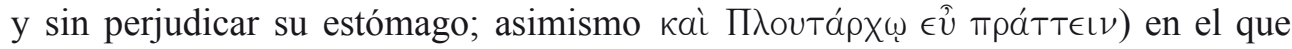

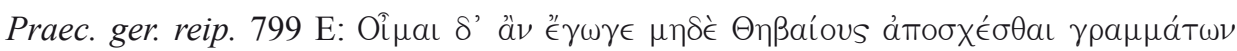

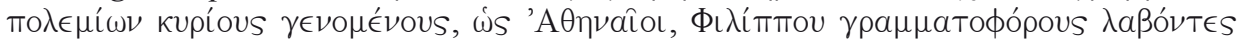

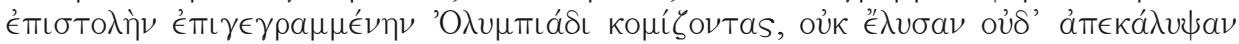

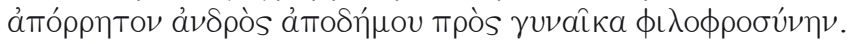

39

La anécdota aparece en la Vida de Demetrio 22.2 -sobre esta carta vid. A. VICENTE SÁnCHEZ, 2007, p. 224- pero con Olimpíade como remitente y Filipo como destinatario.

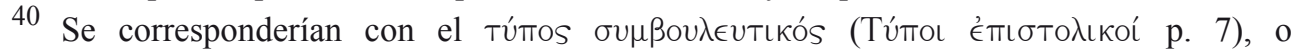

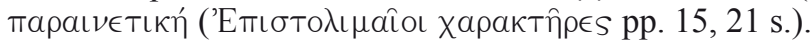

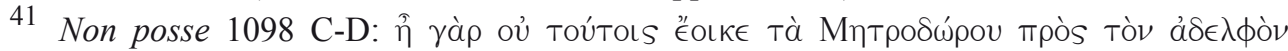

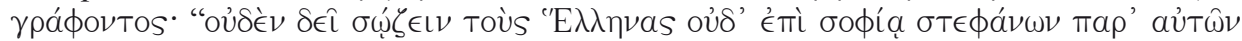

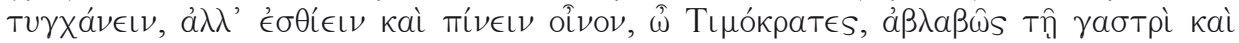

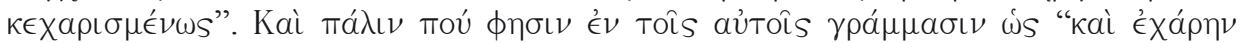

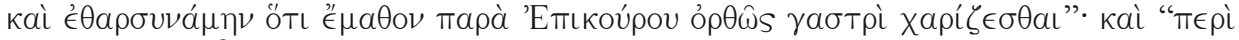

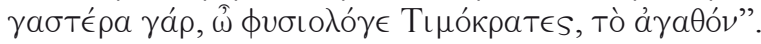

42 Es esta una práctica incluida generalmente en las clasificaciones modernas -vid., por ejemplo, F. X. J. Exler, 1923, pp. 16 ss., J. Sykutris, 1931, cols. 200 ss., J. Schneider, 1954, cols. 568 ss., B. Kytzler, 1965, cols. 497 s., W. G. Doty, 1969, p. 194, Ma . L. BARrio VegA, 1991, pp. 128 ss.; si bien en la preceptiva epistolar de la Antigüedad se aconsejaba moderar la extensión de la carta para que no se convirtiera en un tratado - vid., por ejemplo, Demetr. Eloc. 228 y 231-, no fue una práctica extraña y son abundantes y variados los testimonios que de ella conservamos.

De an. procr. 1012 B-1030 C. 
responde a su petición ${ }^{44}$ de reunir en también protagonista: se sirve Plutarco un único trabajo su interpretación de la de los argumentos tradicionales propios doctrina platónica del alma. Sin embargo del género consolatorio, influidos por su esta "carta" por su extensión ${ }^{45}$ y contenido tendencia platonista, para adaptarlos a filosófico excedería los límites de lo que la las particulares circunstancias familiares. teoría epistolar considera apropiado para Pero este último punto evita que el texto este género, de acuerdo con la opinión sea un mero tratado filosófico puesto de Aristóteles ${ }^{46}$; y, en efecto, tras la que es una carta, enviada al parecer dedicatoria a sus hijos prescinde Plutarco realmente por Plutarco desde Tanagra de cualquier otra referencia al formato como consuelo a su esposa ${ }^{49}$, que le epistolar ${ }^{47}$. En el casode la Consolación ${ }^{48}$, sirve también para mostrarle su amor escrita con ocasión de la muerte de su y devoción, y presentárnosla, además, hija Timóxena, el elemento filosófico es como modelo de mujer y madre. Además

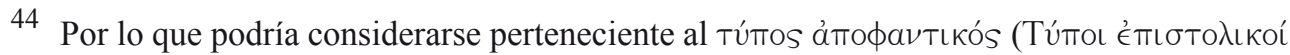

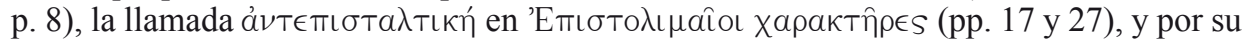

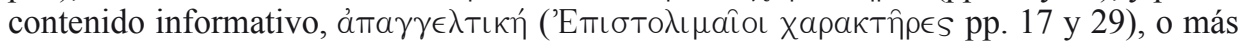

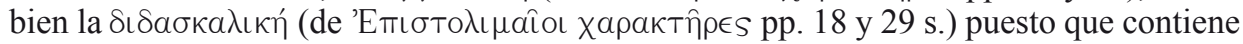
determinadas enseñanzas sobre la opinión de Platón acerca del alma dirigidas a sus hijos (De an. procr. 1012 B).

45 Vid. infra acerca de este asunto.

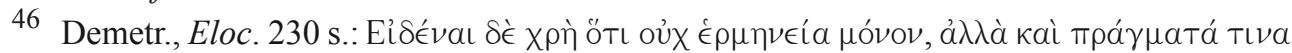

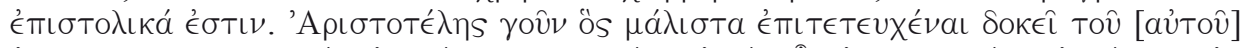

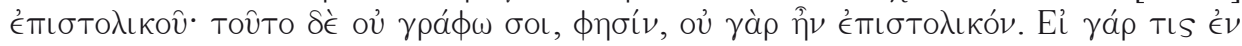

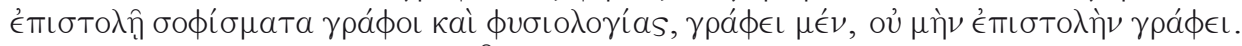

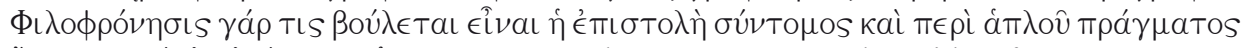

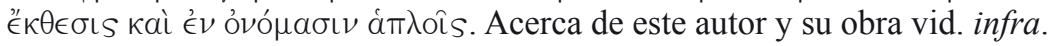

47 El resto está compuesto en tercera persona, salvo algunas referencias en segunda persona del plural: 1012 D, 1027 A, 1020 E, 1022 C, 1028 A. Considera M. L. JR. STIREwALT, 1991, p. 147 ss. y 151 ss., que esta obra forma parte de una categoría especial que él denomina "Greek letter-essay", caracterizada por poseer algún rasgo epistolar pero que "were intended for others in addition to the ones named as addressees" (p. 147), y que complementan por lo general otra obra del mismo autor. Los documentos de esta categoría especial -en la que Plutarco cuenta con varias aportaciones, entre las que no incluye M. L. JR. STIREWALt, el Escrito de consolación a su mujer- comparten una serie de características, como la ausencia de cierre al final del texto, que pueden indicar que Sobre la generación del alma en el "Timeo" -junto a otras "Greek letter-essays"- es una composición que se aproxima a una “covering letter” (M. L. JR. STIREWALt, , 1991, pp. 162 s.).

48 Cons. ad ux. 608 A-612 B.

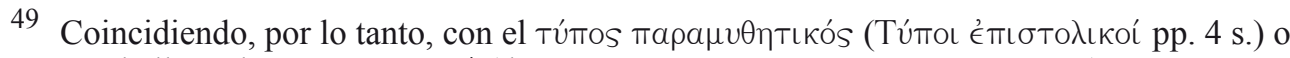

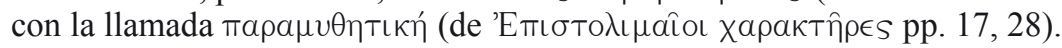


del encabezamiento epistolar (608 A: función de las cartas en el contexto da

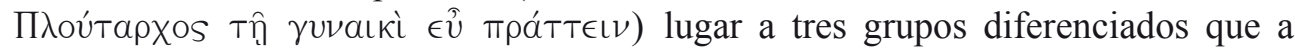
incluye Plutarco referencias a las circuns- continuación van a explicarse. tancias que rodean la composición de la carta $^{50}$, pues el mensajero enviado por su mujer no llegó a contactar con él ${ }^{51}$, quien finalmente se enteró del fallecimiento por medio de otros familiares.

Tras este análisis del contenido de -y, por extensión, al resto de mujeres las cartas objeto de este estudio -y de eleas- como heroína. En este caso es la su correspondencia con los manuales negativa a la redacción de la carta lo que prácticos sobre tipos de cartas- puede ya nos da cuenta del carácter de la persona perfilarse su valor dentro del contexto que debiera escribirla. Este pasaje tiene y del tipo de obra en que se utilizan. lugar en la obra Virtudes de mujeres, una Plutarco incluye estas cartas en Moralia antología de acciones pertenecientes a preferentemente formando parte de una mujeres que, por su tema, se aproxima al narración, anécdota, suceso o similar; elogio fúnebre y al tratado filosófico ${ }^{52}$. Por asimismo suele emplearlas como ejem- su parte, los Consejos políticos pretender plo para sustentar su postura ante determi- ayudar al buen gobernante a conseguir el nadas cuestiones, y en alguna ocasión es $\hat{\eta} \theta$ os apropiado, siendo necesario, para esa su única función, servir de ejemplo. ello, conocer a su vez los distintos $\eta \theta \eta$ de El contenido de las misivas no siempre los pueblos ${ }^{53}$. De ahí que Plutarco añada será importante, sino que a veces serán varios ejemplos de los distintos pueblos y las consecuencias de las mismas o las sus peculiares caracteres, entre ellos el de reacciones que provoquen, lo que interese los tebanos, quienes, si encontraran cartas a nuestro polígrafo. De este modo la de sus enemigos no se comportarían con

50 Este tipo de referencias a los procedimientos que envuelven la composición, escritura y envío de la correspondencia, las estudia y define R. J. Gallé Cejudo como "signos metalingüísticos" -vid. R. J. Gallé Cejudo, 1997, pp. 215 ss.; más tarde P. RosenMeyer, 2001, pp. 204 ss., se referirá a estos mismos elementos como "self-referentiality".

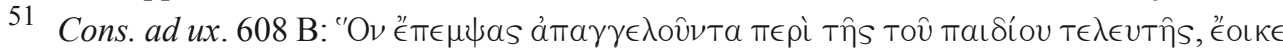

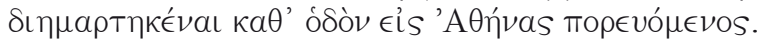

52 Como indica J. Boulogne, 2002, p. 7.

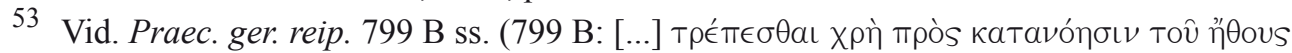

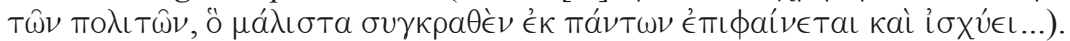


la nobleza de los atenienses cuando no como si de una carta se tratase, confiando leyeron una carta confidencial de Filipo de este modo en su amistad. La anécdota, para Olimpíade ${ }^{54}$. En Máximas de reyes además, se incluye en un pasaje que $y$ generales la lectura de las difamaciones recopila hechos y dichos como muestra vertidas por Olimpíade sobre Antípatro del talante filosófico de Alejandro ${ }^{56}$

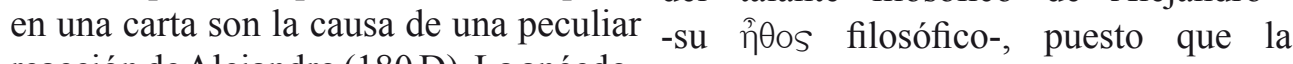
reacción deAlejandro(180 D). La anécdota forma parte, junto a otras treinta y tres, de la serie de dichos que Plutarco atribuye a Alejandro en esta obra cuya dedicatoria manifiesta la utilidad de la colección para comprender los caracteres de los personajes sirviéndose de sus palabras $\mathrm{y}$ prescindiendo de sus acciones ${ }^{55}$. El resto de testimonios de esta misma carta muestra todavía con mayor énfasis el protagonismo de esa reacción que carta sirve para demostrar sus virtudes destaca Plutarco, al no hacer referencia y el buen uso que de ellas hace, pues, al contenido de la epístola. Su uso en el cuando descubre el intento de traición de primer libro de Sobre la fortuna o virtud Filotas ${ }^{62}$, no desvela esa información ni de Alejandro (332 F-333 A), se centra en siquiera a su gran amigo Hefestión, con el acto de sellar el silencio de su amigo quien más confianza tenía, sirviendo de

Praec. ger. reip. 799 E. En el análisis de esta misma anécdota en la Vida de Demetrio 22.2 también se destaca su uso para caracterizar a los personajes -vid. A. Vicente SÁnchez, 2007, p. 224.

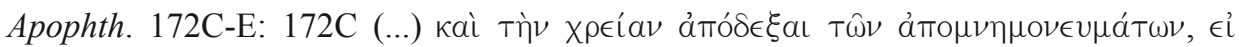

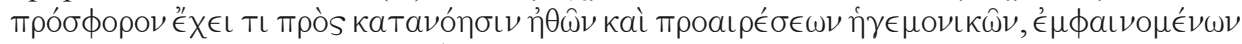

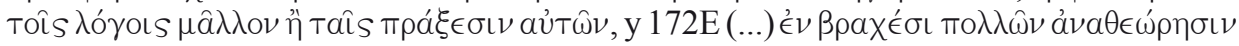

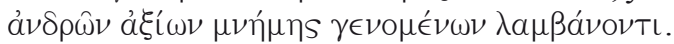

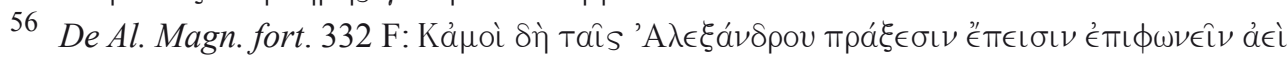

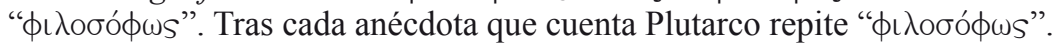

57 Vid. De Al. Magn. fort. 326 D ss.

58 Vid. De Al. Magn. fort. 330 E-332 B.

59 Vid. De Al. Magn. fort. 332 C-333 A.

60 Vid. De Al. Magn. fort. 340 A ss.

61 Vid. De Al. Magn. fort. 337 C-340 A.

62 En esta ocasión se utiliza la anécdota de la carta para fundamentar otro ejemplo, mientras que en los dos casos anteriores, el pasaje era un ejemplo en sí mismo. 
muestra la anécdota de esta carta ${ }^{63}$. Estos eritreos habían ocupado ${ }^{66}$, y es este uno dos últimos testimonios ejemplifican algo de los hechos notorios llevados a cabo específico del carácter de Alejandro ${ }^{64}$, por la muchacha que inducen a Plutarco porque, además, para Plutarco, Alejandro a incluirla en su colección de mujeres cumple la idea estoica de que el sabio lleva virtuosas ${ }^{67}$. Por otro lado, las cartas de a cabo sus acciones con todas las virtudes ${ }^{65}$. Fedra y Gidica son parte de una intriga Todas estas cartas (252 A, $799 \mathrm{E}, 180 \mathrm{D}$, amorosa que acaba con la muerte injusta 332 F - 333 A, 340 A) las usa Plutarco por de sushijastros ${ }^{68}$, en una obra que pretende las repercusiones que tienen en un contexto, demostrar la semejanza de hechos en las no por el contenido de las mismas.

Otro grupo de cartas son importantes tanto por su contenido como por su repercusión en el contexto $(254 \mathrm{D}, 314 \mathrm{~A}$ B y C-D, 109 C-D, 1099 D, 333 A). Así la carta de la naxia Polícrite forma parte del desarrollo de una trama que la hará famosa por recuperar un territorio naxio que los vidas griegas y romanas, el Compendio de historias paralelas griegas y romanas 69 . En tercer lugar, la carta de Eutínoo ${ }^{70}$ es el colofón final para las pesquisas de su padre, cuyo recurso a la necromancia es uno de los distintos ejemplos que Plutarco utiliza para demostrar que la divinidad a veces premia la piedad con el regalo de la

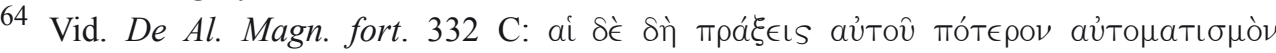

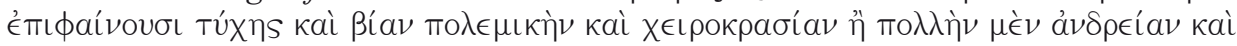

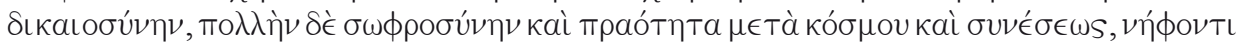

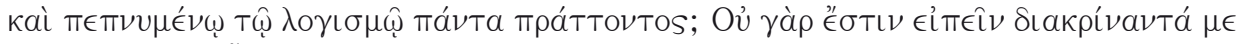

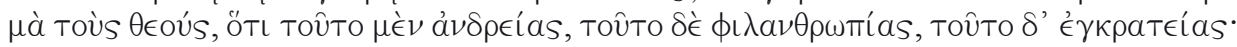

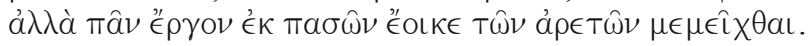

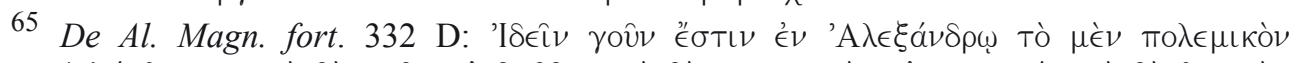

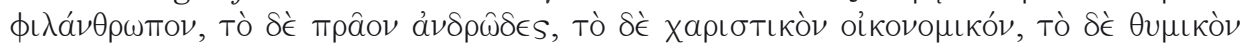

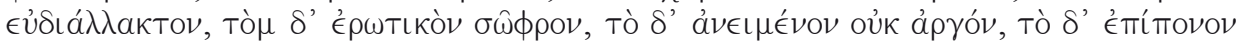

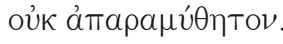

66 Mul. virt. $254 \mathrm{D}$.

67 Mul. virt. 242 F - 263 C. Vid. supra sobre esta obra.

68 Parallel. Graec. et Rom. 314 A-B y B-C.

69 Parallel. Graec. et Rom. 305 A-316 B. Aunque la autoría plutarquea de este texto se pone en duda (cf. J. Boulogne, 2002, p. 238, K. ZIEGLER, "Ploutarchos von Chaironeia", RE XXI [1951], col. 868), podría quizá ser obra de uno de los secretarios de Plutarco a semejanza del método de trabajo de su maestro, publicada probablemente a lo largo de los años que duró 70 la elaboración de las Vidas o poco después (vid. J. Boulogne, 2002, p. 241).

Cons. ad Apoll. 109 C-D. 
muerte $^{71}$. Cierra este grupo la mención de la misiva de Filóxeno ${ }^{72}$ ofreciendo la venta de hermosos muchachos a Alejandro, que será el segundo ejemplo que Plutarco utiliza del macedonio y el tercero en total para demostrar el desprecio que por los placeres corporales sienten los hombres de acción (oi mpakтLKoí). La carta de Filóxeno habría suscitado la censura de Alejandro, por haberle importunado con placeres corporales, porque éstos se desvanecen ante la acción y la ambición de un hombre de estado, que se halla preocupado por cuestiones de mayor envergadura $^{73}$. La misma carta de Filóxeno sirve en otro lugar ${ }^{74}$ para comparar actos de Alejandro con los de filósofos reconocidos (Sócrates, Jenócrates), pero con la respuesta del macedonio en formato epistolar ${ }^{75}$, cuya función en relación con el contexto es distinta y coincide con otro grupo de cartas.

En efecto, esta carta (333 A), junto a Por otra parte, Plutarco, de acuerdo con otras $(760$ C, 1098 C-D, 273 E-F, 241 A, las ideas platónicas, rechaza las teorías

Cons. ad Apoll. $108 \mathrm{E}$ ss.

Non posse $1099 \mathrm{D}$.

Vid. Non posse 1099 B-C.

De Al. Magn. fort. 333 A (primera carta).

De Al. Magn. fort. 333 A (segunda carta).

Acerca de la obra vid. supra el comentario a la carta de De Al. Magn. fort. 332 F-333 A.

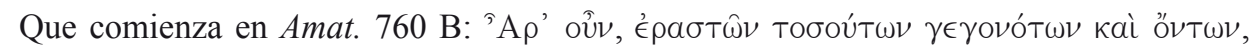

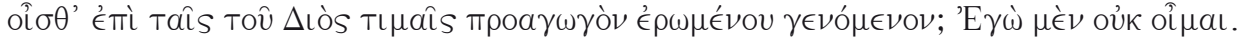
Vid. también la serie de ejemplos que ofrece a continuación.

Porque dice Plutarco que por amor, ni ante los tiranos se cedía: Пó $\theta \in v$ yá $\rho$, ötrov kaì

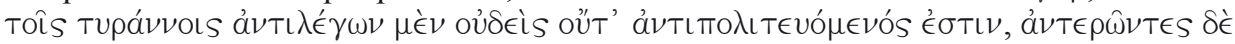

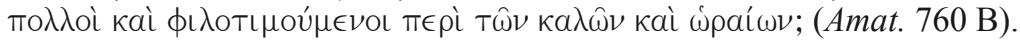

Amat. $760 \mathrm{C}$.

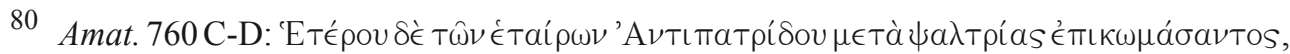

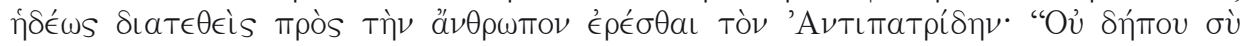


epicúreas $^{81}$, especialmente, como ya se de la romanidad ${ }^{86}$. En este pasaje parte ha señalado antes, los placeres del cuerpo: Plutarco de un ejemplo aparentemente los pasajes de la carta de Metrodoro $^{82}$ real con un personaje conocido, al que se continúan la serie de retazos epicúreos que le van a añadir, a lo largo de la cuestión, Plutarco ofrece como hechos negativos otros ejemplos. Y también dentro de este frente a una actitud vital mucho más correcta (como la de Epaminondas) ${ }^{83}$. En cuarto lugar, el contenido de la carta de Catón el Viejo a su hijo ${ }^{84}$ es el que impulsa al de Queronea a preguntarse por qué el pueblo romano ha de esperar el permiso para matar a un enemigo. La obra en que aparece, Cuestiones romanas ${ }^{85}$, consiste en ciento trece notas sobre la denominación, el comportamiento, los diferentes grupos sociales, aspectos de la vida cotidiana, etc. del pueblo romano, llegando a constituir lo que J. Boulogne ha llamado una "etiología etnológica" grupo podemos incluir las tres cartas de las madres que amonestan a sus hijos ${ }^{87} \mathrm{de}$ una forma muy característica y tradicional de las mujeres espartanas. Sabido es que Plutarco admiraba las viejas costumbres de ese pueblo y por ello no es de extrañar que confeccionara una recopilación de apophthegmata independientes, Máximas de espartanos ${ }^{88}$, útil para emplearla en otras partes de su obra ${ }^{89}$.

Finalmente destaca la singularidad de la carta de consolación a su esposa ${ }^{90}$, que no sólo no forma parte de un relato o

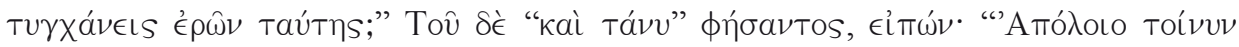

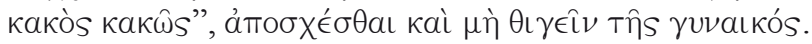

81 Acerca de la postura de Plutarco ante las doctrinas epicúreas, vid. J. F. Martos Montiel, "Plutarco transmisor de la filosofía epicúrea: el Contra Colotes entre polémica y didáctica", en A. Casanova (ed.), Plutarco e l'età Ellenistica. Atti del Convegno Internazionale di studi Firenze (23-24 Settembre 2004), Florencia, 2005, pp. 336- 350.

82 Non posse $1098 \mathrm{C}-\mathrm{D}$

83 Vid. Non posse 1098 A ss.

84 Quaest. Rom. 273 E-F.

85 Quaest. Rom. 263 D - 291 C.

86 J. Boulogne, 2002, p. $92 \mathrm{~s}$.

87 Apopht. Lac. 241 A, 241 D, 241 D-E.

88 Apopht. Lac. 208 A-242 D, cuya parte final está dedicada a las mujeres espartanas (240 C - 242 D).

89 Al igual que haría con Máximas de reyes y generales; sobre este uso vid. A. VICENTE SÁnCHEZ, "Plutarco compositor de Vitae y Moralia: análisis intratextual", en A. G. Nikolaidis, The Unity of Plutarch's Work, Berlín - Nueva York, 2008, p. 215 s.

90 Cons. ad ux. 608 A-612 B. 
ficción, sino que es real y personal, puesto racteres que presenta, aunque en ocaque, como ya se ha comentado, parece siones el uso de una carta como medio ser que efectivamente Plutarco envió la de comunicación es poco o nada imepístola a su esposa mientras él regresaba portante y sean sus consecuencias, las de un viaje. Por otra parte no sabemos reacciones que levanta a su alrededor, el si el propio Plutarco la publicó, práctica motivo que le impulsa a incluirlas en su habitual para las cartas de este género, el redacción. Tenemos así cumplido uno consolatorio, en cuyo caso pudo haberla de los objetivos principales que la teoría retocado y completado. También se ha retórica y epistolar ${ }^{91}$ reconocen en la considerado que el texto fuera hallado epistolografía, a saber, el reflejo del $\hat{\eta}^{\dagger} \theta$ os, entre los papeles de Plutarco por sus bien a través de la propia carta, bien del descendientes o incluso que fuera espurio, contexto en el que aparece. En efecto, algo avalado por el hecho de que en los el más antiguo manual de ejercicios manuscritos figura con diferentes títulos. escolares que conservamos, el de Teón ${ }^{92}$,

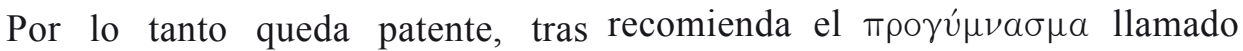
este escueto análisis de nuestras cartas prosopopeya para la composición de y del contexto en el que se incluyen, cartas $^{93}$. Y en este ejercicio, llamado en que Plutarco, cuando recurre a un los manuales posteriores etopeya, era testimonio epistolar, suele servirle esencial la descripción de caracteres:

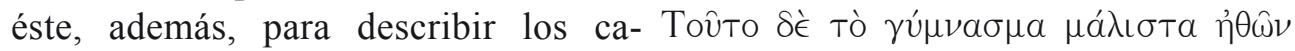

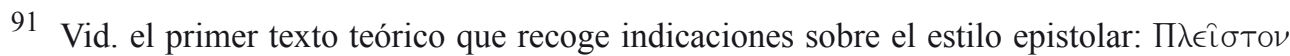

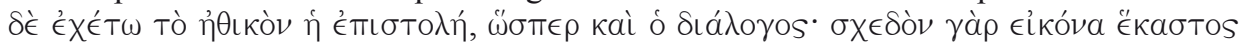

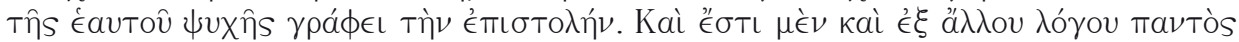

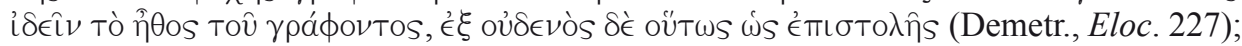
también es común esta idea entre los epistológrafos, vid. por ejemplo la Carta a Aspasio de Filóstrato al hacer referencia a las Cartas de Marco Aurelio: Kaì tò ÉSpaîov toû

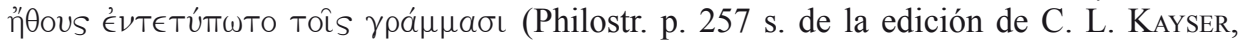
1871). Sobre la importancia y desarrollo del topos de la carta como imagen del alma, vid. W. G. MüLler, "Der Brief als Spiegel der Seele. Zur Geschichte eines Topos der Epistolartheorie von der Antike bis zu Samuel Richardson", A\&A, 26 (1980), pp. 138 ss.

92 Compuesto quizá en el siglo I o entre finales del siglo I y principios del II; cf. R. F. Hock \& E. N. O’Neil, 1986, p. 10; G. A. KenNedy, 1972, pp. 615 s., y 1983, pp. 54 ss. y Progymnasmata: Greek textbooks of prose composition and rhetoric, Leiden, 2003, pp. XII s. y 1; M. PAtILlon, 1997, pp. VIII ss. En este trabajo se da crédito a la datación tradicional del manual de Teón en torno al siglo I; para propuestas más tardías, vid. M. HeAth en "Theon and the history of the Progymnasmata", GRBS, 43, (2000/3), pp. 129 ss.

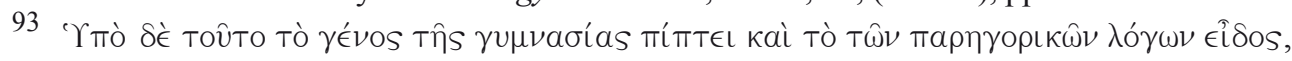

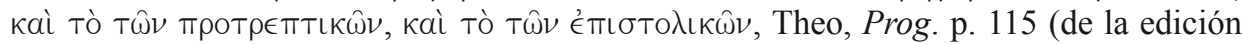
de M. Patillon, 1997, aunque conservando la numeración de la canónica de L. Spengel, 1854); vid. también Nicol., p. 67 (de la edición de I. Felten, 1913). 


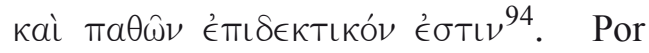
su parte, Plutarco era consciente de esa utilidad de la epistolografía para transmitir caracteres, pues él mismo lo reconoce con frecuencia; pueden servir de ejemplo sus palabras en la Vida de

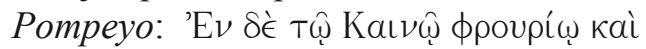

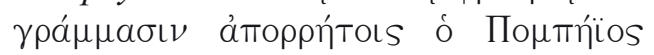

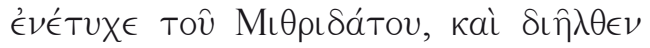

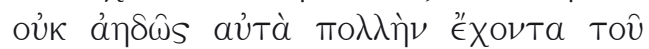

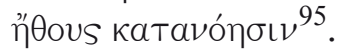

Pero no sólo puede describirse el carácter del remitente en una epístola, sino que también puede transmitirse el del destinatario, y así se especifica en

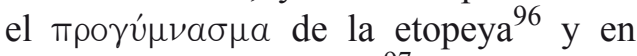
la preceptiva epistolar ${ }^{97}$ : algunas de las cartas que aquí estudiamos reflejan muy claramente el $\hat{\eta} \theta 0 s$ del remitente y del destinatario, como el de las estrictas madres espartanas y el de sus informales $\operatorname{hijos}^{98}$ (241 A, 241 D, 241 D-E); el $⿱ \hat{\eta} \theta$ os

94 Theo, Prog. p. 117, y lo mismo en el siguiente manual conservado, el de Hermógenes de Tarsos (durante la Antigüedad tardía, la época Bizantina y el Renacimiento, fue probablemente el retórico griego más leído y de mayor influencia; cf. G. A. KenNEDY, 1972, pp. 619 ss.; R. F. Hock \& E. N. O’Neil, 1986, p. 11): Hermog., Prog. p. 21 (edición de H. Rabe, 1913) sobre la autoría de este manual vid. E. RuIz YAMuZA, "Hermógenes y los Progymnasmata: problema de autoría", Habis 25, 1994, p. 285ss. y "Más sobre los Progymnasmata atribuidos a Hermógenes”, Habis, 31 (2000), p. 293 ss.;- vid. asimismo Nicol., Prog. p. 64 y 67.

95 Plu., Pomp. 37.1. Más ejemplos en Eum. 11.2, donde Plutarco termina una descripción del aspecto físico y de la forma de ser de Eumenes haciendo referencia a lo que sus cartas

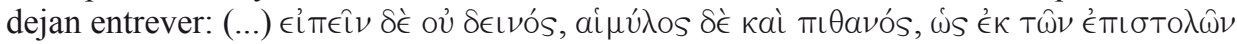
$\sigma v \mu \beta a ́ \lambda \lambda \in \iota \nu \epsilon^{\prime} \sigma T^{\prime} \nu$. Un intercambio epistolar entre César y Antonio lo utiliza el primero para

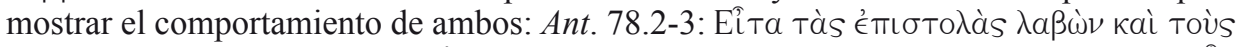

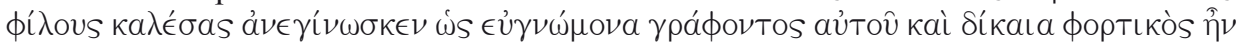

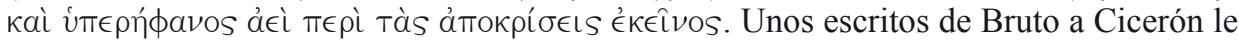
sirven a Plutarco para describir su comportamiento en las primeras cartas (Brut. 23.1: 'Ev

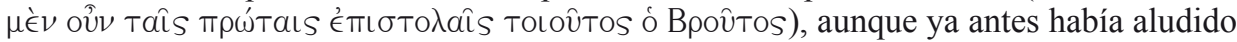
a su forma de escribir cartas citando algunas de ellas con la intención de completar la

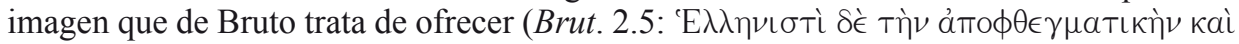

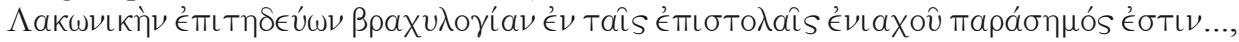

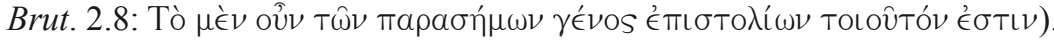

La etopeya dice que deben elaborarse los discursos - que, no olvidemos (Theo, Prog. 115), pueden ser cartas- en virtud tanto del carácter del emisor como del receptor (vid. Theo, Prog. 115); y Hermógenes nos habla de etopeyas simples -dirigidas a uno mismo- y dobles

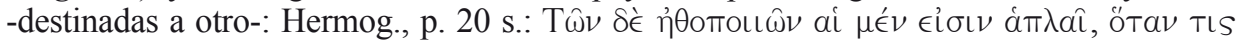

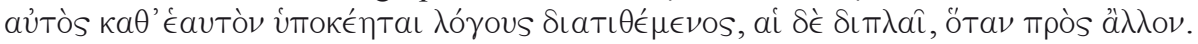

97 También Demetrio destaca la importancia del carácter del destinatario (Demetr. Eloc.

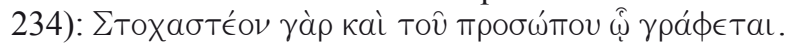

98 Hermógenes habla de etopeyas determinadas e indeterminadas (Hermog., Prog. p. 20); los testimonios de las madres espartanas (241 A, 241 D, 241 D-E) serían variaciones de 
de Catón el Viejo y el de su hijo soldado, y, En estas últimas cartas (180 D, $332 \mathrm{~F}$ por extensión, el del pueblo romano (273 333 A, 340 A, 252 A, 314 A-B y C-D, 799 E-F); el epicúreo Metrodoro aleccionando E), cuyo contenido es menos importante a su hermano sobre las mejores opciones que la función de la epístola en el contexto,

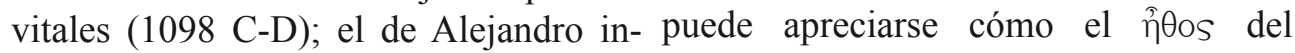
teresado por la amiga de Teodoro, si a éste destinatario aparece más difuminado, $\mathrm{y}$, en no le importa (760 C); el del héroe moral Alejandro respondiendo a las deshonestas intenciones del desvergonzado Filóxeno (333 A, la segunda carta); el de este último ofreciendo un bello muchacho con gran naturalidad a un rey (333 A y 1099 D); el de un hijo fallecido reprendiendo a su padre que ha osado ir a buscarlo al mundo de los muertos (109 C-D); el de una valiente muchacha ${ }^{99}$ que, para salvar a su pueblo de una ocupación enemiga y de una tiranía, trama un engaño para avisar a sus hermanos que se encuentran al acecho (254 D); el de una madre ambiciosa que desea proteger y encumbrar a su conquistador hijo (180 D especialmente, pero también $332 \mathrm{~F}$ - 333 A y 340 A); el de una esposa valiente y patriota que debería escribir, forzada por el tirano, a su marido y resto de exiliados que pretenden recuperar la ciudad desde una favorable fortificación (252 A); el de sendas esposas despechadas -sus hijastros las han rechazado- para sus incautos y crédulos maridos (314 A-B y C-D); el de un marido ausente en campaña militar que escribe a su esposa (799 E). ocasiones, incluso el del remitente (sobre todo en $799 \mathrm{E}$ ). Y es que, evidentemente, cuanto más importa el contenido de la

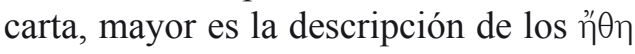
de remitente y destinatario y mayor es también la autonomía e independencia del contexto en que Plutarco utiliza cada carta. Sin embargo, resulta que aquellas cartas que parecen más parcas en cuanto a la transmisión del îं $\theta$ os, se insertan en contextos u obras cuya finalidad es la descripción de un carácter determinado, con lo que, de alguna manera, se suple esa ausencia debida a la poca importancia que se presta al contenido mismo de la carta. En efecto, ya se ha comentado cómo la carta mencionada en 799 E se utiliza en Consejos políticos, que pretende definir el $\hat{\eta} \theta$ os del buen gobernante, quien, a su vez, ha de conocer los $\ddot{\eta} \theta \eta$ de los distintos pueblos. Y lo mismo puede afirmarse de otras obras que contienen epístolas de amor y familiares: Máximas de reyes y generales $(180 \mathrm{D})$, Virtudes de mujeres (252 A), Sobre la fortuna o virtud de Alejandro (332 F - 333 A y 340 A), Compendio de historias paralelas griegas y romanas (314 A-B y C-D).

la segunda clase de etopeyas y el siguiente, con Catón el Viejo como remitente (273 E-F), de las determinadas.

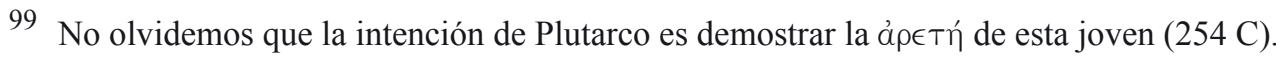


Finalmente merece comentario aparte uno-; a todo ello, además, se suma la la descripción del remitente ${ }^{100}$ y sobre conveniencia de adecuar el texto a cada todo del destinatario que se lleva a cabo circunstancia particular ${ }^{105}$. Así puede en el Escrito de consolación a su mujer, apreciarse en el billete que recibe Elisio de hasta el punto de que gran parte de la su hijo Eutínoo, escrito en verso -aunque epístola es en realidad una descripción de no puede confirmarse su pertenencia a su esposa como paradigma femenino ${ }^{101}$.

De modo que en sus epístolas recoge Plutarco distintos caracteres, que varían según la clase y el estado ${ }^{102}, \mathrm{y}$ consigue transmitir sentimientos y modos de ser, que, según explican Aristóteles en su por adaptar los testimonios epistolares a Retórica ${ }^{103}$ o Teón en su manual de los personajes y a las circunstancias son ejercicios preparatorios ${ }^{104}$, dependen de los pertenecientes a las madres anónimas la capacidad de mostrar la clase -edad, en las Máximas de mujeres espartanas sexo, procedencia- y el estado -lo que que critican y censuran a sus respectivos caracteriza la forma de vivir de cada hijos, pues nuestro autor modela el

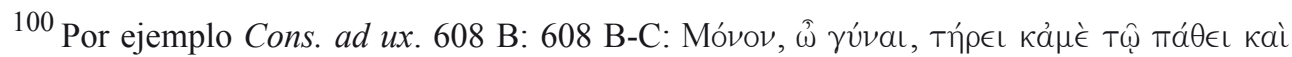

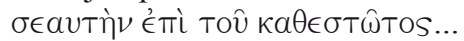

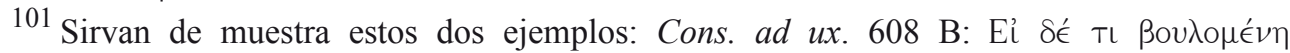

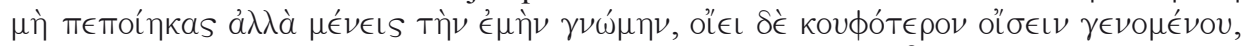

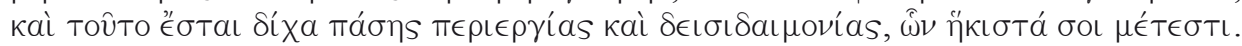

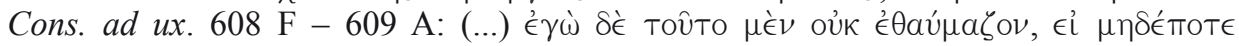

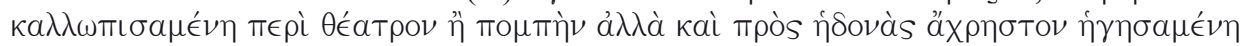

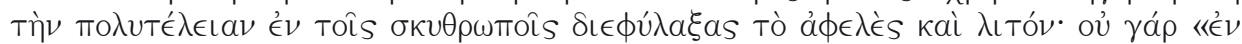

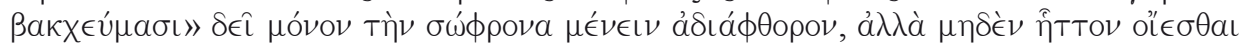

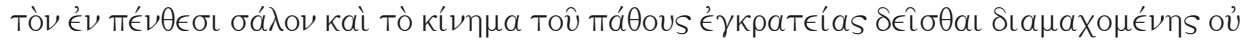

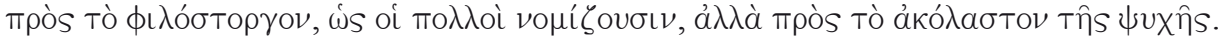

Piénsese en las diferencias entre las cartas de las enfadadas madres espartanas, la de Catón el Viejo a su hijo, las de Fedra y Gidica a sus maridos o la del propio Plutarco a su cultivada esposa.

103 Vid. Arist., Rh. III 7 (1408 a 10 ss., 27 ss., 30 ss.).

104 Theo, Prog. pp. 115 s.

105 Así en los manuales de progymnasmata Theo, Prog. pp. 115 s., o Hermog. Prog. p. 21;

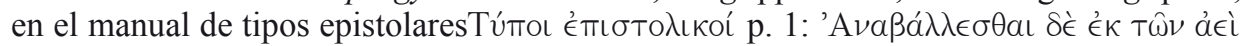

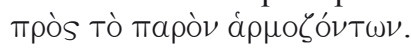

${ }^{106}$ Por ejemplo los oráculos. Sobre esta cuestión vid. A. Vicente SÁnchez, “Un mensaje del más allá: Cons. ad Apoll. 109 C-D” (en prensa). 
griego para que sea el propio de una en la obra del queronense; por ejemplo, espartana, por ejemplo, al mantener que también escribía, pues en la obra la abertura de la original $\alpha(/ \bar{a} /)$ que en Deberes del matrimonio ${ }^{110}$ se menciona jónico-ático cerraba en $\eta(/ \overline{\mathrm{e}} /)$ como en: su ensayo П€

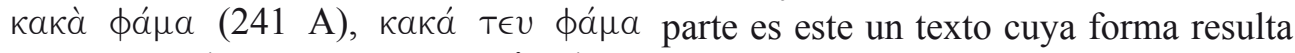

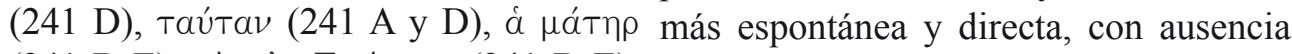

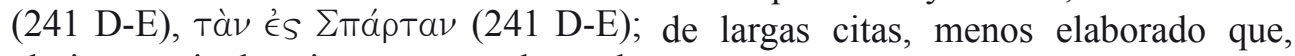
el cierre articulatorio - $\in \mathrm{U}$ - procedente de por ejemplo, el Escrito de consolación a - $\in$ O- en: $T \in U$ (241 A y D), ámó $\in \in U$ (241 Apolonio (101 F - 122 A). Estos rasgos D); o el apócope y asimilación de la que denotan una mayor sencillez, se han preposición кaTá al formar compuestos utilizado en ocasiones para sustentar (fenómeno muy raro en la prosa jónico- la teoría de que Plutarco escribiría esta ática): какке́Xutal (241 A y D) ${ }^{107}$. Y en la Consolación vemos cómo adapta Plutarco conocidos tópicos literarios ${ }^{108}$ a su propio caso especialmente en los consejos que ofrece a su mujer ${ }^{109}$. Quizás podría pensarse que el tono filosófico de la carta es demasiado elevado para estar dirigido a una mujer de aquella época, pero no debe olvidarse que Timóxena era, carta ya desde Tanagra, de forma rápida y nada más recibir la triste noticia ${ }^{111}$. Sin embargo, ese número de citas menor de lo habitual en sus obras puede responder simplemente a las exigencias del estilo epistolar ${ }^{12}$, al que Plutarco procura adaptar su escrito con cierta fidelidad.

Por lo tanto, respecto de la función de sin duda, una persona cultivada, tanto por las cartas de amor y familiares en Moralia, la descripción que de ella hace Plutarco se destaca sobre todo su caracterización en esta carta, como por otras referencias del $\hat{\eta} \theta 0 s$ de los personajes y su adecuación

${ }^{107}$ Vid. C. D. Buck, The Greek dialects, Chicago - Londres, 1973 (=1955), pp. 21, 40, 81 s. y 83.

${ }^{108}$ Acerca de los modelos retóricos y literarios de los que pudo servirse Plutarco, vid. F. Lillo Redonet, 1996, pp. 159 ss.

${ }^{109}$ Así en $608 \mathrm{~F}$ (aprovechar nuestros propios razonamientos que hemos dirigido a otros en nuestra misma situación), 609 C (la inutilidad de los actos irracionales), 609 E-F, 610 B-C (el rechazo a las demostraciones de duelo exageradas e irracionales), $610 \mathrm{D}$ (pensar en el tiempo anterior al nacimiento del hijo y en lo que supuso dicho nacimiento), 611 A (la pena es una pasión y uno no debe dejarse arrastrar por ella), $611 \mathrm{~B}$ (su vida es envidiable, no debe malgastarla), 611 C-D (desarrollo de los tópicos tradicionales acerca de la muerte prematura).

${ }^{110}$ Con. praec. $145 \mathrm{~A}$.

111 Vid. en F. Lillo Redonet, 1996, pp. 158 s., opiniones a favor y en contra de dicho argumento.

112 Vid. supra e infra los comentarios sobre la preceptiva epistolar y sus recomendaciones (evitar los contenidos altamente filosóficos, ofrecer una extensión moderada, buscar claridad y concisión en la forma y en el estilo, etc.) 


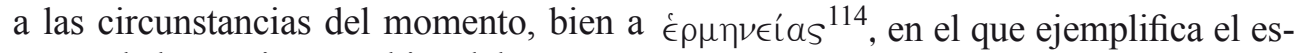
través de la propia carta, bien del contexto tilo íxvós o simple con la escritura de en el que Plutarco la incluye. Pero no será cartas, aunque éstas también pueden comeste el único rasgo en el que coincidan las ponerse siguiendo los dictados del estilo

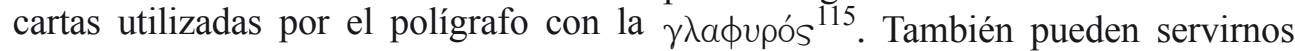
preceptiva epistolar griega. La tradición de fuente para este asunto los comentarios nos ha conservado como primer $^{113}$ tes- de algunas composiciones literarias ${ }^{116}$, sotimonio teórico sobre la epistolografía bre todo la Carta a Aspasio de Ravena ${ }^{117}$, un capítulo del manual de estilo $\Pi \in \rho i$ atribuida a Filóstrato ${ }^{118}$.

113 Aunque no existen pruebas certeras de la exacta datación de este manual; con frecuencia se parte del siglo III a.C. en los diversos estudios -cf. G. M. A. Grube, A Greek critic: Demetrius on style, Toronto, 1961, pp. 39ss., 56s., 133ss. G. Morpurgo-Tagliabue, Demetrio: dello stile, Roma, 1980, pp. 141 ss. y 146ss.; E. SuÁrez DE LA TORRE, 1988, p. 189-, aunque suelen aceptar que podría retrasarse entre uno y hasta tres siglos más tarde, $\mathrm{y}$, en ocasiones, se prefiere esta datación más tardía -cf. D. M. SchenKeveld, Studies in Demetrius "On style”, Amsterdam, 1964, p. 147s.; K. Thraede, 1970, pp. 19 ss.-, G. A. Kennedy, en S. E. Porter, 1997, p. 27; W. Wuellner, “Arrangement”, en S. E. Porter, 1997, p. 64.

114 Atribuido erróneamente a Demetrio de Falero; cf. G. A. Kennedy, The art of persuasion in Greece, Londres, 1963, pp. 285 ss.; E. SuÁrez de la Torre, 1979, pp. 31 s.; A. J. MalHerbe, 1988, p. 2.

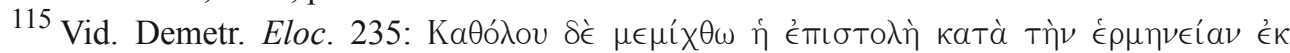

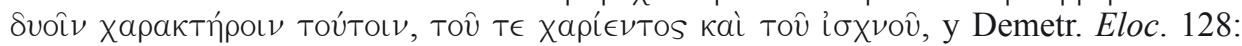

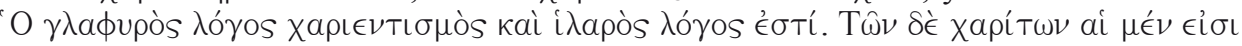

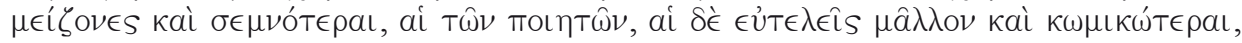

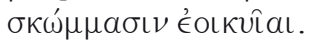

${ }^{116}$ Así hace referencia al estilo epistolar la Carta 19 atribuida a Apolonio de Tiana, incluyendo

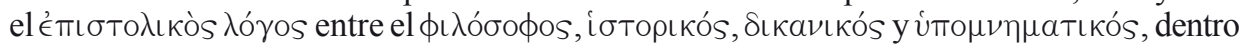

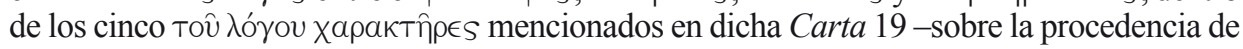
las Cartas atribuidas a Apolonio de Tiana, vid. E. L. BowIE, "Apollonius of Tyana: Tradition and Reality”, $A N R W$ II 16.2, Berlín-Nueva York, 1978, pp. 1671 ss. y 1691 s.

117 También de datación incierta, entre fines del siglo II y el siglo III -vid. H. HungER, 1978, p. 199; J. T. ReED, 1997, p. 173. Esta Carta a Aspasio, que sería posterior a Plutarco, recoge nociones tradicionales sobre la escritura de cartas en la Antigüedad, y así parece constatarlo la mención de los mismos tópicos tanto en la teoría griega anterior como en autores literarios; vid. G. SCARPat, 1972, pp. 477 s.; J. L. White, 1986, pp. 190 ss.; P. Cugusi, 1990, pp. 383 s.

118 Y que parece que sería familia del Filóstrato autor de la Vida de Apolonio de Tiana y las Vidas de Sofistas -quien también hará referencias a la escritura de cartas, vid. Philostr. VS. 24 y 33 . Vid. sobre los distintos "Filóstratos" cf. H. Koskenniemi, 1956, pp. 29 s.; A. R. BenNer \& F. H. FoBes, The Letters of Alciphron, Aelian and Philostratus, Cambridge (Massachusetts), 1962 (=1949), pp. 387ss.; G. Anderson, Philostratus. Biography and belles lettres in the third century A.D., Londres-Sidney-Dover (New Hampshire), 1986, pp. 291 ss. 
Una de las características principales del estilo epistolar es que la carta puede considerarse la mitad de una conversación $^{119}$, hasta el punto de que algunos autores creen conveniente escribirlas del mismo modo que un diálogo ${ }^{120}$,

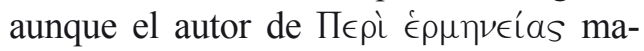
nifiesta ciertas reservas a este respecto, ya que, en su opinión, el estilo epistolar no pero escrita con cuidado ${ }^{121}$. La forma de estas cartas de Plutarco, que recoge algunas en estilo indirecto y otras las reproduce en parte o completamente, coincide a grandes rasgos con la de una conversación: uso de vocativos ${ }^{122}$, ruegos y órdenes ${ }^{123}$, preguntas $^{124}$, expresión directa, etc.

Dos aspectos que la reflexión sobre la debe ser tan laxo como el diálogo; ha de epistolografía siempre destacó, como se tener la frescura de la palabra improvisada ha avanzado más arriba, son la sencillez

${ }^{119}$ E. Suárez de la Torre explica cómo los conceptos más representativos de la Lingüística estructural pueden aplicarse perfectamente a la epistolografía: "el esquema tradicional de los factores del lenguaje (hablante, tema o mensaje y oyente) pueden ser traspasados perfectamente considerando el carácter lineal de la esquematización de la carta sobre los términos emisor - mensaje (con código) - receptor”, E. SuÁREZ DE LA TORRE, 1979, p. 21. Para este "proceso de comunicación" epistolar en el que la ausencia de correspondencia "hace que no exista la simetría de roles para ambos interlocutores", propone R. J. Gallé Cejudo hacer referencia al fenómeno epistolar como uno de "dialogismo", "definido como un proceso de comunicación caracterizado por la presencia de dos sujetos, uno de los cuales puede permanecer latente, estar a distancia, ser un ente de ficción, etc., donde basta con que el emisor actúe con la idea de que otro va a entrar en el proceso para decodificar su discurso", R. J. Gallé CEJUdo, "La carta ficticia griega y el diálogo", ExcPhilol, 4-5 (1994-95), p. 42.

${ }^{120}$ Así pensaría Artemón, citado por Demetrio como editor de las cartas de Aristóteles,

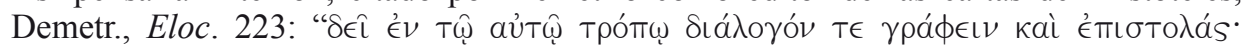

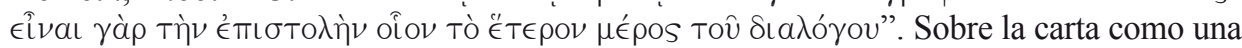
mitad de una conversación, cf. F. X. J. ExLer, 1923, p. 15; K. Thraede, 1970, p. 126; W. Schadewaldt, 1973, p. 32; E. SuÁrez de la Torre, 1979, p. 37 s.; J. G. Altman, Epistolarity. Approaches to a Form, Ohio, 1982, pp. 135 ss.; P. Cugusi, 1990, p. 383; R. J. Gallé Cejudo, Aristéneto, Cartas eróticas: introducción, traducción y notas, Madrid, 1999, pp. 22, 42 ss.

${ }^{1}$ Vid. Demetr., Eloc. 224 ss.: así las oraciones inconexas características del diálogo no son

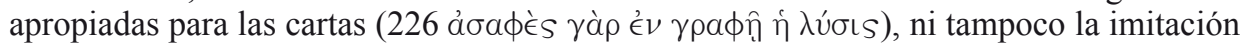

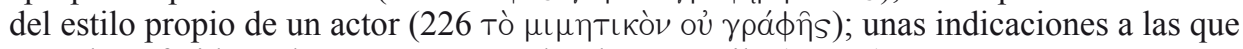
ya se ha referido en las normas generales de este estilo (193ss.).

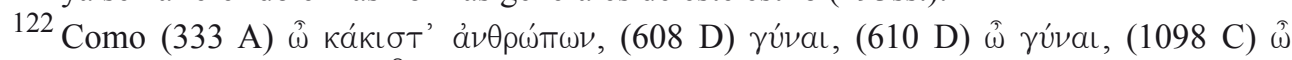

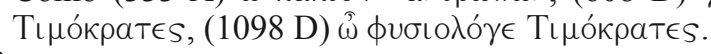

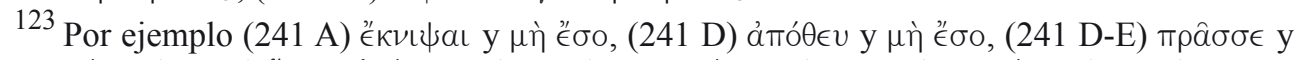

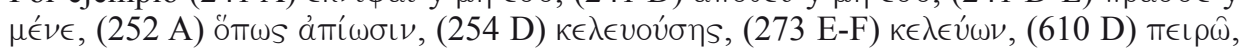

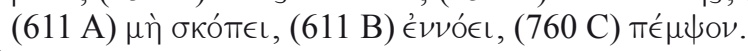

${ }^{124}$ En 273 E-F, en sendas cartas de 333 A, en 1099 D. 
y la claridad ${ }^{125}$, ya que la persuasión se basa en la claridad y lo cotidiano ${ }^{126}$. Así el estilo simple según el manual $\Pi \epsilon \rho i$

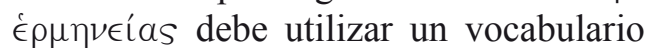
habitual y corriente ${ }^{127}$, -evitándose los compuestos, las nuevas creaciones, las propias, en fin, de un estilo elevado ${ }^{128}$ pero, dado que el género epistolar tiene en cuenta también el estilo gracioso ${ }^{129}$, las palabras habrán de ser bellas ${ }^{130} \mathrm{y}$ no demasiado vulgares, pues quedaría entonces ridículo ${ }^{131}$. Las cartas que Plutarco incluye en sus tratados morales hacer referencia a versos irregulares de presentan, por lo general, un vocabulario la poesía homérica, o $609 \mathrm{E} \pi \epsilon \rho i ́ \theta \lambda a \sigma \iota \nu$

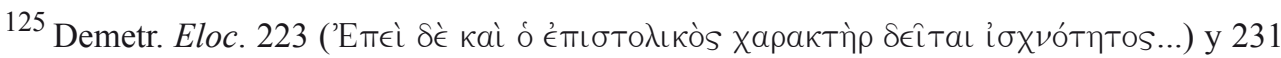

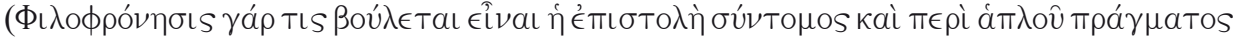

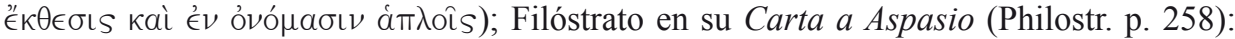

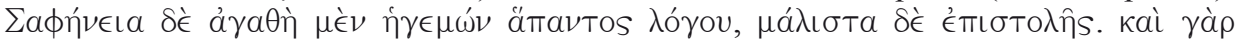

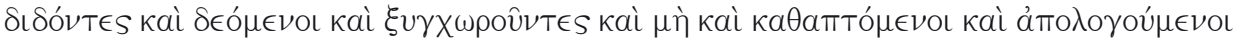

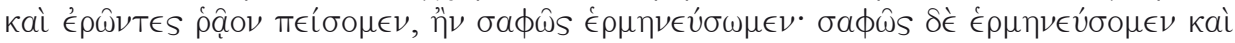

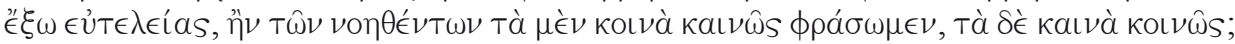

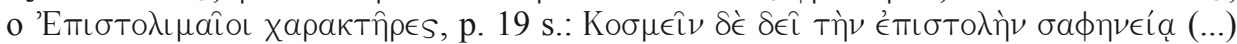

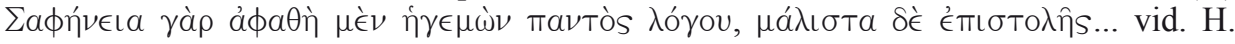
KoskenNiemi, 1956, pp. 21 ss.

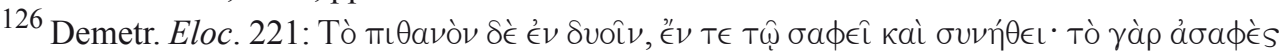

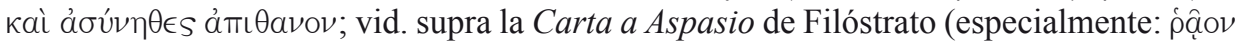

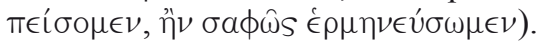

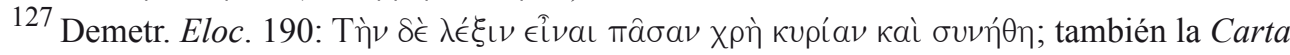
a Aspasio recomienda un vocabulario corriente (vid. supra).

128 Demetr., Eloc. 191 ss.

${ }^{129}$ Y también confieren "gracia" a este estilo los términos cotidianos (vid. Demetr., Eloc.

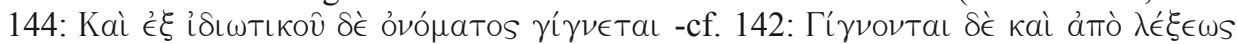

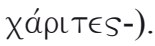

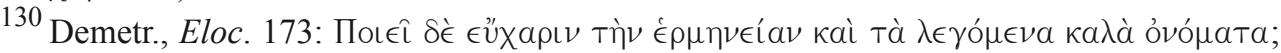

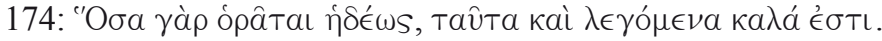

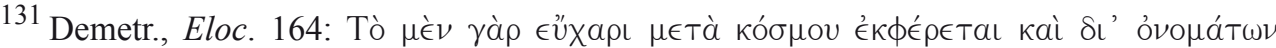

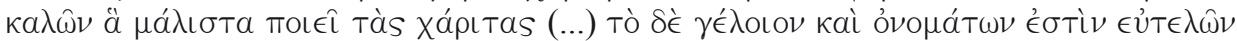
кai коเvоте́ $\omega \nu$. Sobre este término medio entre elevado y coloquial habla también

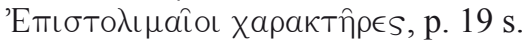


término médico que designa un mal que En relación con la preceptiva claridad sufrió la esposa de Plutarco, a los que exigida para una carta se halla la comse añade algún otro compuesto como posición sintáctica, sobre la que en $\Pi \epsilon \rho \grave{~}$

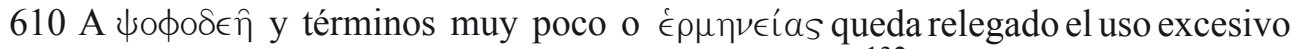
nada utilizados en la literatura griega del asíndeton ${ }^{132}$ por atribuirlo al diálogo conservada pero que, por otra parte, son hablado pero no al escrito ${ }^{133}$, aunque frecuentes en la obra dePlutarco como 610 en opinión de algunos literatos, como el

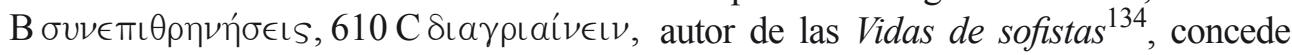
$609 \mathrm{~F} \delta v \sigma \epsilon \xi\lfloor\lambda a \sigma \tau \alpha$. Aunque parezca que esplendor al estilo epistolar. Sin embargo, se aleja de lo convenido para una epístola tampoco sería propio de este género una con estos usos peculiares, no debemos composición trabada y pomposa, nos dice olvidar el tono íntimo con que Plutarco se la preceptiva ${ }^{135}$, por lo que la expresión ha dirige a su esposa, persona cultivada como de ser suelta ${ }^{136}$, sin llegar al asíndeton, por ya se ha comentado más arriba, por lo que un lado, y, por otro, prescindiendo de los no han de extrañar estos excesos léxicos períodos ${ }^{137}$. Así nuestras cartas son claras con los que ella estaría bien familiarizada, y sencillas, evitando el asíndeton y trabadas de modo que es esta una nueva prueba de pero sin llegar al uso de períodos, salvo la adaptación de su forma de escribir a las algún pasaje de la Consolación un poco más circunstancias del momento. elaborado, que combina la hipotaxis y la

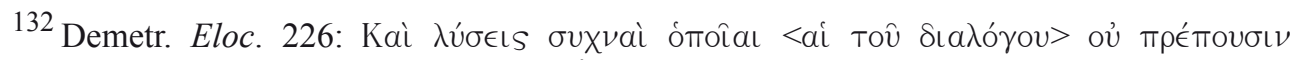

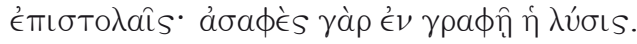

${ }^{133}$ Vid. Demetr. Eloc. 192-193.

${ }^{134}$ Filóstrato aprueba la claridad y concisión del estilo epistolar de Antípatro el sofista de

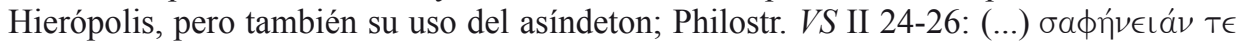

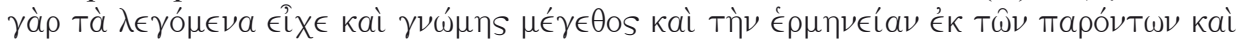

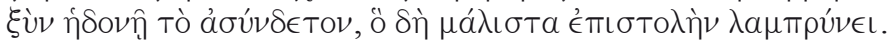

135 Además, en relación con el estilo vehemente comenta Demetrio del asíndeton que es más simple y representa mejor un carácter bondadoso que la periodización; Demetr., Eloc.

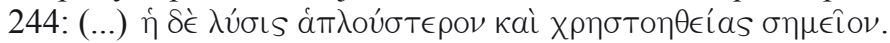

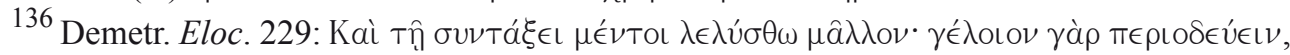

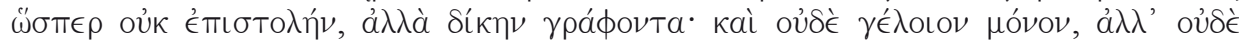

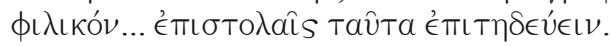

137 También la Carta a Aspasio de Ravena hace referencia a los períodos en la epistolografía, desaconsejando su uso en general y limitándolos a cartas muy breves o al final de los

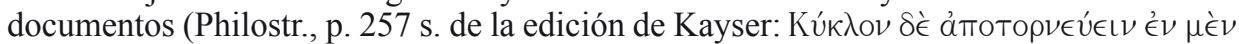

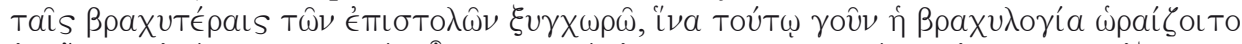

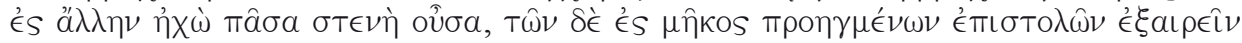

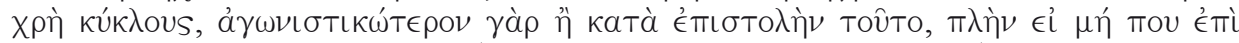

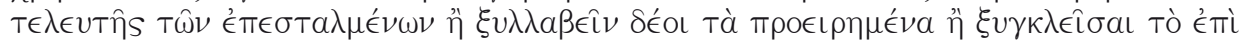

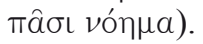


parataxis a través de miembros breves ${ }^{138}$.

Otro elemento importante en la composición de cartas es la inclusión de expresiones de amistad y proverbios, que, además, son propios de los dos estilos que caracterizan la epístola, el "simple" y el "elegante"139. De su uso nos da abundantes muestras sobre todo la Consolación a su mujer ${ }^{140}$.

Siguiendo con la definición de carta como breve testimonio de amistad ${ }^{141}$, están de acuerdo las indicaciones teóricas más antiguas en preferir la concisión para los documentos epistolares ${ }^{142}$, puesto que ésta, además, confiere xápıs, la característica principal de uno de los estilos apropiados para la epistolografía ${ }^{143}$. En más común de hacer referencia a las cartas las cartas aquí estudiadas se sigue esta es el verbo $\gamma \rho a ́ \phi \omega$ y compuestos $(241 \mathrm{~A}$

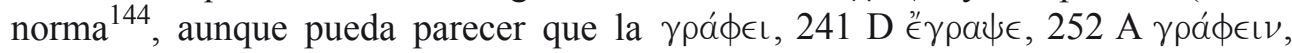

${ }^{138}$ Véase por ejemplo 608 B o 611 B-C.

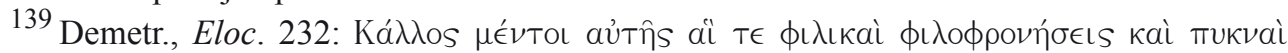

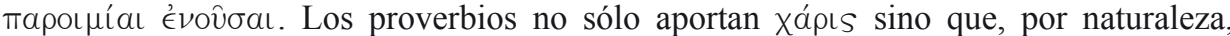

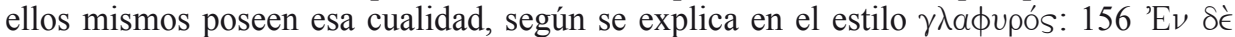

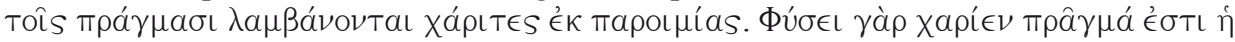

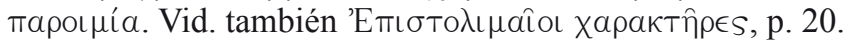

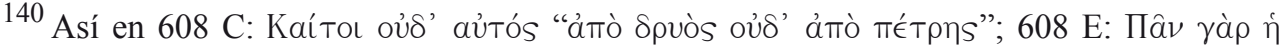

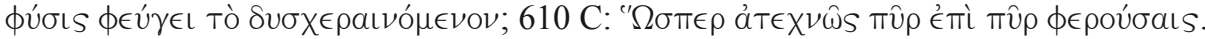

${ }^{141}$ Vid. supra Demetr. Eloc. 230-231.

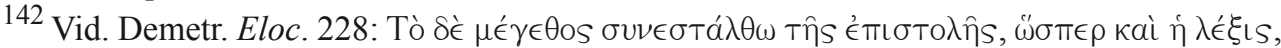

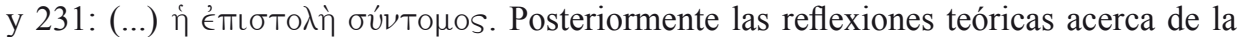
concisión admitirán documentos más amplios cuando su contenido así lo precise, vid.,

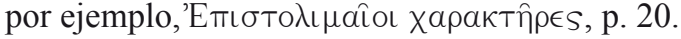

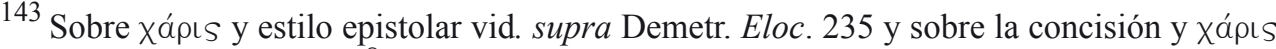

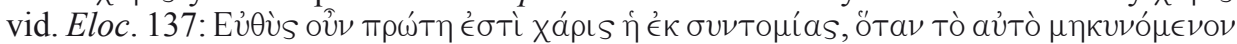

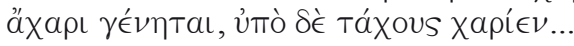

${ }^{144}$ Siempre en las cartas transmitidas en estilo directo (109 C-D, 241 A, 241 D, 241 D-E, 333 A, 760 C, 1098 C-D, si bien este último pasaje recoge solamente fragmentos de una carta). 


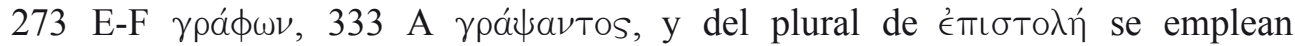

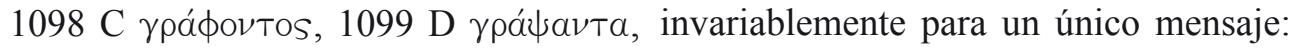

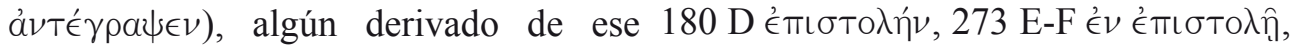

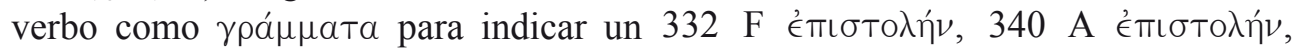

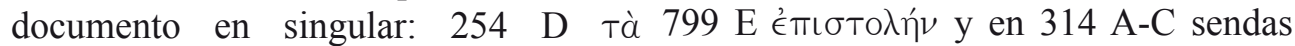

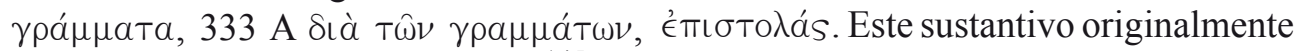
799 E $\gamma \rho \alpha \mu \mu \alpha ́ \tau \omega \nu ; \gamma \rho \alpha \mu \mu \alpha \tau_{i ́ \delta} \delta \nu^{145}$ en hacía referenciaa órdenes orales o escritas, el texto de $254 \mathrm{D}$ y también en $109 \mathrm{C}-\mathrm{D}$, en asuntos oficiales y militares, y esta aunque la mayoría de las ediciones ${ }^{146}$ en idea de orden permanece después en las lugardel $\gamma \rho \alpha \mu \mu a \tau i ́ \delta$ เov delosmanuscritos cartas personales cuando consisten en una aceptan una corrección de Wilamowitz: petición ${ }^{149}$. En tragedia se utiliza siempre

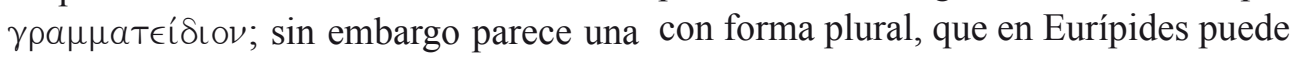
corrección un tanto gratuita, puesto que hacer referencia a un mensaje escrito; en los demás usos que Plutarco efectúa Tucídides -generalmente para despachos de este término mantienen todas las militares- usará indistintamente singular ediciones ${ }^{147}$ la forma de los manuscritos y plural para un sólo documento, aunque

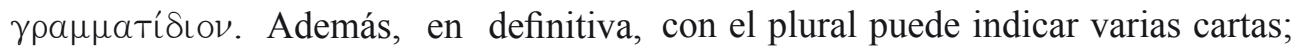
ambas formas parecen tener el mismo en autores posteriores comenzarán a significado y suele explicarse que sendas aparecer documentos personales desigterminaciones remiten al mismo sufijo nados con este término y quedará fijado el con distinta grafía ${ }^{148}$. Asimismo se puede uso del singular para una carta y el plural hacer referencia a cartas mediante el para más de una. M. L. Jr. Stirewalt ${ }^{150}$ verbo $\epsilon \pi \iota \sigma T \epsilon ́ \lambda \lambda \omega$ y otros derivados: 241 explica su forma plural de épocas más D-E É $\pi \epsilon ́ \sigma T \epsilon L \lambda \epsilon \nu$; las formas del singular tardías en referencia a un sólo documento

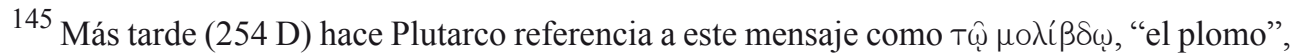
metonímicamente, puesto que ya ha explicado antes que ese era el soporte utilizado

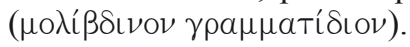

146 Así lo señalan la ediciones de W. R. Paton, \& I. Wegehaupt, 1974 y J. Defradas \& J. Hani

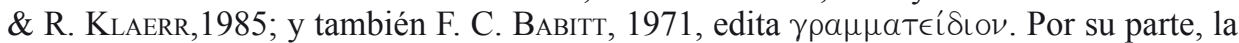
edición de G. N. BERNARDAKIS, 1908, conserva la forma original de los manuscritos.

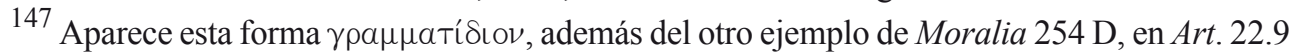
y en Brut. 5.3 para un mensaje escrito con remitente y destinatario, mientras que en Lys. 16.1 la emplea para indicar la nota que se halla dentro de unos sacos de plata indicando a su destinatario la cantidad exacta de metal que contenía cada uno de esos sacos.

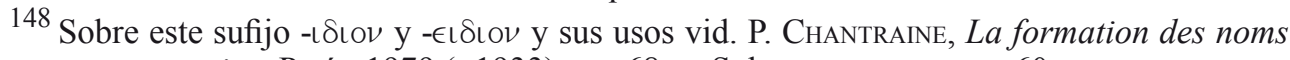
en grec ancien, París, 1979 (=1933), pp. 68 ss. Sobre -€เov e -ıov, p. 60 s.

149 Cf. M. L. JR. Stirewalt, 1993, p. $62 \mathrm{~s}$.

${ }^{150}$ M. L. JR. StiREWALt, 1993, pp. 71 ss., vid. asimismo p. 11. 


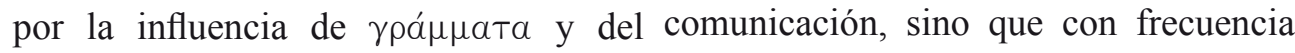
latín litterae, algo que justificaría el uso le sirve de elemento argumental, de

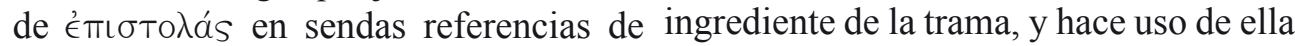
314 A-C; pero quizás también pueda como una pieza más de la vida corriente deberse este uso plural para señalar una de las personas.

única carta a que un famoso texto cuenta esa misma historia, a saber, Eurípides en su tragedia Hipólito, v. 858, donde

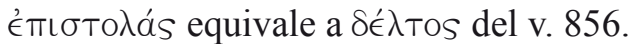

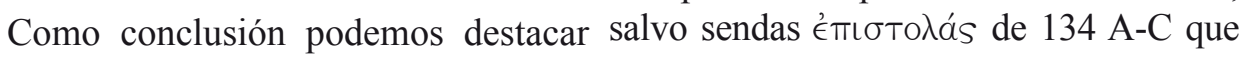
que la epistolografía amorosa y familiar pueden deberse, ya se ha comentado, bien pertenece a una clase de cartas especial a una influencia analógica, bien a una e importante en la vida social diaria, literaria. En otros aspectos formales se en la que se hallan completamente integradas como demuestran sus variados usos en Moralia de Plutarco. Si bien este tipo de intercambio epistolar era ya frecuente desde época Clásica ${ }^{151}$, corresponde nuestra selección de cartas en líneas generales con aquello que aconsejan los teóricos epistolares y retóricos más cercanos en el tiempo a Plutarco. podemos, asimismo, comprobar cómo documentos de Plutarco coincide con en el tiempo de Plutarco se mantenía los tipos epistolares que los manuales vivo y funcional. Pero, además, puede prácticos recogían desde hacía tiempo, destacarse el importante papel que en y, además de adaptarse a los requisitos la literatura desempeña entonces la que los teóricos proponían para su forma, epistolografía, convertida en un elemento están en consonancia igualmente en lo habitual en las composiciones literarias, que a la función se refiere. Sobre esta ya que incluso en tratados morales no es última queremos destacar una vez más raro encontrar distintos tipos de cartas, la importancia que tiene el elemento incluso aquellos que pertenecen a la vida epistolar a la hora de colaborar en la privada, como hemos visto aquí. Plutarco descripción y caracterización del î̉ $\theta$ os de usa la epistolografía no sólo por sí misma, un personaje o un colectivo, y, asimismo, como género literario o como medio de cómo Plutarco se sirve de este recurso

151 Cf. M. L. JR. Stirewalt, 1993, pp. 11 s.

${ }^{152}$ A lo ya comentado puede añadirse que también coincide, sobre todo en lo que a los términos más generales se refiere, con la terminología empleada en la epistolografía

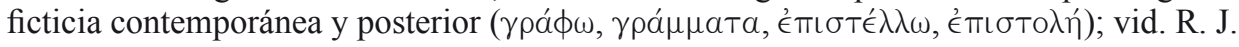
Gallé Cejudo, 1997, pp. 225 s. 
con dicha intención ${ }^{153}$.

Al hilo de esta relación entre epistolografía y contexto resulta forzoso subrayar el aura de magia, exotismo y secreto que envuelve a la comunicación epistolar: en época Clásica no es raro encontrar reservado el recurso de la epistolografía a ocasiones relevantes o secretas, como testimonian las obras de Heródoto, Tucídides o Eurípides, en las que aparece con frecuencia relacionada con traiciones, engaños e incluso muertes $^{154}$. Y es que en la civilización griega antigua, el que podría llamarse efecto "mágico" de la palabra hablada, veía aumentado su valor al comunicar a seres alejados espacialmente mediante la escritura de cartas; los testimonios literarios nos confirman que el mundo griego era consciente de este fenómeno y que se servía artísticamente de él ${ }^{155}$. Del corpus que aquí se estudia un gran número de cartas están relacionadas con algún plan secreto, artimaña o asunto oscuro. Así el mensaje que Polícrite subrepticiamente consigue hacer llegar a sus hermanos dentro de una torta durante un enfrentamiento bélico (254 D); el engaño que el tirano invasor Aristotimo pretende llevar a cabo a través de una carta de Megisto (252 A); las críticas secretas de Olimpíade en una carta a Defradas, J., Hani, J. \& Klaerr, R., Alejandro que éste consigue mantener - Plutarque. Oeuvres morales, II, París, 1985.

${ }^{153}$ Esta misma función destaca en el uso que Plutarco hace de las cartas relacionadas con el amor en su obra biográfica; vid. A. Vicente SÁnchez, 2007, pp. 225 ss.

154 Cf. W. Schadewaldt, 1973, pp. 32 s.; W. V. Harris, Ancient literacy, Cambridge (Massachusetts)-Londres, 1989, pp. 88 s., 127; P. Rosenmeyer, 2001, p. 27.

155 Cf. E. SuÁrez de la Torre, 1988, pp. 179 s.

como tales sellando los labios de su amigo (180 D, $332 \mathrm{~F}$ - $333 \mathrm{~A}, 340 \mathrm{~A})$; las palabras dolosas de Fedra y Gidica (314 A-B y C-D); las críticas de un hijo hacia un padre que se ha atrevido a buscarlo en el mundo de los muertos recurriendo a los ritos mágicos de la necromancia (109 D); la venta de personas con fines sexuales (1099 D, primera carta de $333 \mathrm{~A}, 760 \mathrm{C}$ ).

\section{Bibliografía}

BabitT, F. C., Plutarch's Moralia, II, Londres - Cambridge, Massachusetts, 1971 (=1928).

Barrio Vega, Ma ${ }^{a}$. L. Del,

"Algunos problemas de la epistolografía griega. ¿Es posible una clasificación epistolar?", Minerva, 5 (1991) 123-137.

BERNARDAKIS, G. N.,

- Plutarchus. Moralia, I, Leipzig, 1908.

Boulogne, J.,

- Plutarque. Oeuvres morales, IV, París, 2002.

Chiron, P.,

- Démétrios: du style. Introduction, texte, traduction, París, 1993.

Cugusi, P.,

"L' epistolografia: modelli e tipologie di comunicazione", en Lo spazio letterario di Roma Antica, II, Roma, 1990, pp. 379-419.

Cuvigny, M.,

Plutarque. Oeuvres morales, XI - Deuxième partie, París, 1984

PLOUTARCHOS, n.s., 6 (2008/2009) 53-82

ISSN 0258-655X 
Doty, W. G.,

- "The classification of epistolary literature", The Catholic Biblical Quarterly, 31 (1969) 183-199.

Einarson, B. \& LACy, P. H. DE,

- Plutarch's Moralia, XIV, Londres - Cam- bridge, Massachusetts, 1967.

EXLER, F. X. J.,

- The form of the ancient Greek letter. A study in Greek epistolography, Washington, 1923.

Felten, I.,

- Nicolai Progymnasmata, Leipzig, 1913.

Flacelière, R.,

- Plutarque. Oeuvres morales, X, París, 1980.

- Frazier, F. \& Froidefond, C.,

- Plutarque. Oeuvres morales, V - $1^{\text {re }}$ partie, Malherbe, A. J., París, 1990.

FuHrmann, F.,

- Plutarque. Oeuvres morales, III, París, 1988.

Gallé Cejudo, R. J.,

- "Signos metalingüísticos referentes al marco formal en la epistolografía griega", Habis, 28 (1997) 215-226.

Hani, J.,

- Plutarque. Oeuvres morales, VIII, París, 1980.

Hock, R. F. \& O’NeIL, E. N.,

- The chreia in ancient rhetoric. Volume I. The Progymnasmata, Atlanta, 1986

Hunger, H.,

- Die Hochsprachliche profane Literatur der Byzantiner. Erster Band: Philosophie, Rhetorik, Epistolographie, Geschichtsschreibung, Geographie, München, 1978.

KaYser, C. L.,

- Flavii Philostrati opera, II, Leipzig, 1871.

Kennedy, G. A.,

- The art of rhetoric in the Roman world, 300 B. C. - A. D. 300, Princeton, 1972.

Greek rhetoric under christian emperors, Princeton, 1983
- Ancient epistolary theorists, Atlanta, 1988.

PATILlon, M.,

Koskenniemi, H.,

Studien zur Idee und Phraseologie des griechischen Briefes bis $400 \mathrm{n}$. Chr., Helsinki, 1956.

KYTZLER, B.,

"Brief", Lexicon der alten Welt (ZürichStuttgart, 1965), cols. 496-501.

Lillo Redonet, F.,

"La Consolatio ad uxorem de Plutarco y la tradición de la consolación femenina", en J. A. Fernández Delgado \& F. Pordomingo Pardo (eds.), Estudios sobre Plutarco: aspectos formales. Actas del IV Simposio Español sobre Plutarco (Salamanca, 26 a 28 de mayo de 1994), Madrid, 1996, 157-165.

- Progymnasmata. Aelius Théon, París, 1997.

Paton, W. R. \& Wegehaupt, I.,

- Plutarchi Moralia, I, Leipzig, 1974.

PERrin, B.,

- Plutarch's lives, V, Londres - Cambridge, Massachusetts 1968.

- Plutarch's lives, VIII, Londres - Cambridge, Massachusetts 1969

- Plutarch's lives, VI, Londres - Cambridge, Massachusetts 1970.

- Plutarch's lives, IX, Londres - Cambridge, Massachusetts 1978.

Porter, S. E. (ed.),

- Handbook of classical rhetoric in the hellenistic period 330 BC - AC 400, Leiden - Nueva York - Colonia, 1997.

RABE, H.,

- Rhetores Graeci, VI: Hermogenis Opera, Leipzig, 1913.

REED, J. T.,

- “The epistle", en S. E. Porter , 171-194.

Rosenmeyer, P.,

- Ancient epistolary fictions: the letter in Greek literature, Cambridge, 2001. 
SCARPAT, G.,

SuÁrez de la Torre, E.,

- "L'epistolografia", Introduzione allo stu- - "La epistolografía griega”, EClás, 83 dio della cultura clasica, I, Milán, 1972, 472-512.

SchadewALDT, W.,

- "Der Brief bei den Griechen. Ein Instru(1979) 19-46.

- “Ars Epistolica.Lapreceptiva epistolográfica y sus relaciones con la retórica", en G. Morocho Gayo (ed.), Estudios de drama y retórica, León, 1988, pp. 177-204. ment des Humanen", en E. Hora \& E. Sykutris, J., Kessler (eds.), Studia Humanitatis. Ernes- - "Epistolographie", RE Suppl. 5 (1931), to Grassi zum 70. Geburtstag, Munich, 1973, pp. 31-42.

SCHNEIDER, J.,

- “Brief”, RLAC 2 (1954), cols. 564-585.

Spengel, L.,

- $\quad$ Rhetores Graeci, II, Leipzig, 1854.

Stirewalt, M. L. JR.,

- "The form and function of the Greek letteressay", en K. P. Donfried (ed.), The Romans debate, Edimburgo, 1991 (=MinneapolisAugsburgo, 1977) 147-171. cols. 185-220.

Thraede, K.,

- Grundzüge griechisch-römischer Brieftopik, Munich, 1970.

Vicente SÁnchez, A.,

- "El amor y la epistolografía en la obra biográfica de Plutarco", en J. Ma Nieto Ibáñez \& Raúl López López (eds), El amor en Plutarco, León, 2007, pp. 219-228.

WEICHERT, V.,

- Demetrii et Libanii qui feruntur Túmo

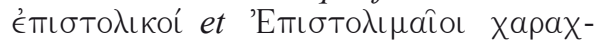
тทिрєS, Leipzig, 1910.

- Studies in ancient Greek epistolography, White, J. L., Atlanta, 1993.

- $\quad$ Light from ancient letters, Philadelphia, 1986. 